\title{
Nicomachus-Positive Parenting (NPP): Development and Initial Validation of a Parenting Questionnaire within the Positive Psychology Framework
}

\author{
Theodoros A. Kyriazos, Anastassios Stalikas \\ Department of Psychology, Panteion University, Athens, Greece \\ Email: th.kyriazos@gmail.com
}

How to cite this paper: Kyriazos, T. A., \& Stalikas, A. (2019). Nicomachus-Positive Parenting (NPP): Development and Initial Validation of a Parenting Questionnaire within the Positive Psychology Framework. Psychology, 10, 2115-2165.

https://doi.org/10.4236/psych.2019.1015136

Received: November 2, 2019

Accepted: December 24, 2019

Published: December 27, 2019

Copyright ( $) 2019$ by author(s) and Scientific Research Publishing Inc. This work is licensed under the Creative Commons Attribution International License (CC BY 4.0).

http://creativecommons.org/licenses/by/4.0/

\begin{abstract}
After operationalizing the positive psychology parenting construct, following the model proposed by Seligman in Authentic Happiness, a new questionnaire called NICOMACHUS-Positive Parenting (NPP) was developed and validated. The validation process was completed in three studies. In Study 1 $(N=190)$ theoretically, relevant items were reduced, refined, and tested resulting in a measure with 20 items. In Studies $2(N=621)$ and $3(N=146)$ the psychometrics of NICOMACHUS were validated and cross-validated respectively. A clear, robust four-factor structure was defined and confirmed with EFA and CFA respectively. Full measurement invariance across the child's gender was successfully established to the strict level. Internal consistency reliability $(\alpha)$, model-based reliability $(\omega)$ and convergent validity at the model level (AVE) were excellent and comparable across methods. Convergent/discriminant validity with 6 parenting measures revealed a highly significant, uniform relationship pattern. In Study 3 the above findings were successfully cross-validated by stable, similar findings. Convergent/discriminant validity with 5 measures of wellbeing and affect also revealed a highly significant, clear relationship pattern. The relationship of NICOMACHUS with demographics was also examined. NICOMACHUS adds to the existing parenting measures, allowing parents to evaluate if their parenting practices follow the principles of Positive Psychology.
\end{abstract}

\section{Keywords}

Parenting, Positive Parenting, Positive Psychology, Wellbeing, Test Construction, Test Development, Test Validation, Psychometrics, Greece 


\section{Introduction}

Seligman (2002), meticulously described a model of parenting effectiveness, based on the principles of Positive Psychology. Despite that, to the best of our knowledge, this parenting model received less attention than the rest of the Authentic Happiness model components (2002). To hopefully promote research in this area, a first step would be developing a new measure of Positive Psychology parenting, operationalizing this Authentic Happiness parenting model (Seligman, 2002). Therefore, the purpose of this study is to describe the development and validation of a new measure of Positive Psychology Parenting (Nicomachus-Positive Parenting or NPP).

\subsection{Definitions of Terms Used}

A Parent is a person with whom a child has a long-term, unique and irreplaceable biological, social and emotional bond (Tobach \& Schneirla, 1968; Rohner, Khaleque, \& Cournoyer, 2012).

A family is a group of interacting people with a similar intention (Conoley \& Conoley, 2009; Conoley, Conoley, \& Pontrelli, 2014) or an open system of people (von Bertalanffy, 1976). Family systems are grounded on the General Systems Theory (von Bertalanffy, 1976), suggesting that families are studied more effectively when taking into account member interactions and environmental effects (Whiteman et al., 2011).

Parenting is a bidirectional, biological and social process (Tobach \& Schneirla, 1968) between members of at least two generations within a specific cultural context (Ford \& Lerner, 1992; Lerner, Rothbaum, Boulos, \& Castellino, 2002).

Positive Psychology. Martin Seligman, as APA president announced the Positive Psychology movement on August 21, 1999 (Seligman \& Csikszentmihalyi, 2000) for the empirical study of "what makes life worth living" (Peterson, 2013; Seligman, 2011). The purpose of Positive Psychology is to study all factors contributing to human flourishing on both a personal and a community level (Gable \& Haidt, 2005; Linley \& Joseph, 2015). Positive Psychology brought about a change in the outlook of "psychology as usual" (Seligman \& Pawelski, 2003; Hefferon \& Boniwell, 2011; Seligman, Railton, Baumeister, \& Sripada, 2016) that can also affect parenting practices (Seligman, 2002).

Character strengths are a sub-category of personality attributes having moral value, e.g. politeness as opposed to introversion which has no moral dimension (Peterson \& Park, 2009). Fredrickson defines character strengths as habits (Fredrickson, 2009). The most frequently used strengths are called signature strengths (measured with Values in Action Inventory of Strengths, Peterson \& Seligman, 2004).

Positive emotions here are used within the Broaden and Built theoretical framework (Fredrickson, 1998, 2001). After two decades of extensive research there is a top-ten of positive emotions: joy, gratitude, serenity, interest, hope, pride, fun, inspiration, awe and love (Fredrickson, 2009; Hefferon \& Boniwell, 2011). 
Well-being is a positive evaluation of one's own life (Seligman, 2002; Diener \& Seligman, 2004), while Ryan \& Deci (2001) and Seligman (2002; Seligman \& Csikszentmihalyi, 2000) link well-being with optimum experience (Flow; Csikszentmihalyi, 1990) and psychological functioning (Mitchell, Vella-Brodrick, \& Klein, 2010).

Flourishing is a state of positive mental health where the person is both feeling well and doing well in personal and social level, free from mental illness (Keyes, 2002; Fredrickson \& Losada, 2005; Seligman, 2011).

\subsection{The Positive Psychology Parenting and the Model behind NICOMACHUS}

For Seligman (2002), parenting offers parents the chance to: 1) Apply the principles of Positive Psychology; 2) Increase the level of positive emotions to the child; 3) Discover strengths and signature strengths and then nurture these signatures strengths; 4) To increase the well-being of the child and the entire family 5) Forge a child's life around his/her signature strengths as a means of balancing his/her weaknesses and flourishing. According to Seligman (2002), two core elements that enable children to flourish are: 1) positive emotions as described within the Broaden and Build Theory (Fredrickson, 1998, 2001), and 2) the character strengths (Seligman \& Csikszentmihalyi, 2000; Peterson \& Seligman, 2004). These are the two pillars of positive psychology parenting (Seligman, 2002). Seligman (2002) implicitly adopts the systemic view on parenting and family (von Bertalanffy, 1976), placing them in the center of a wide interactive relationship pattern with environment factors (like school, job, hobbies, marital and social relations). The environment contributes to personal and family wellbeing (as a part of the good life; see also Seligman, 2004) on certain conditions: abundant positive emotions in the parent-child relationship and the use of strengths in all realms of child life.

The proposed model of positive psychology parenting as defined by Seligman (2002) (see also Kyriazos \& Stalikas, 2018a).

Seligman (2002) postulates the three fundamental principles of Positive Psychology Parenting (see Table 1).

The three principles (Table 1) are integrated into a model of positive psychology parenting (Seligman, 2002). This model is essentially focused on building child positive emotions first and then tracing and in turn nurturing character strengths (see Figure 1):

Table 1. The three principles of positive psychology parenting in the authentic happiness model by Seligman (2002).

\begin{tabular}{cl}
\hline Principle 1 & $\begin{array}{l}\text { Positive emotions broaden and build (Fredrickson, 1998, 2001) cognitive, social, } \\
\text { emotional and physical resources on which children can rely when in adversity. }\end{array}$ \\
Principle 2 & $\begin{array}{l}\text { Increasing positive emotions in children can initiate upward spirals of } \\
\text { positive emotions according to the Broaden and Build theory of } \\
\text { Positive Emotions (Fredrickson, 1998, 2001). }\end{array}$ \\
Principle 3 & The positive traits of children are as important as the negative ones. \\
\hline
\end{tabular}

Source: Kyriazos \& Stalikas, 2018a. 


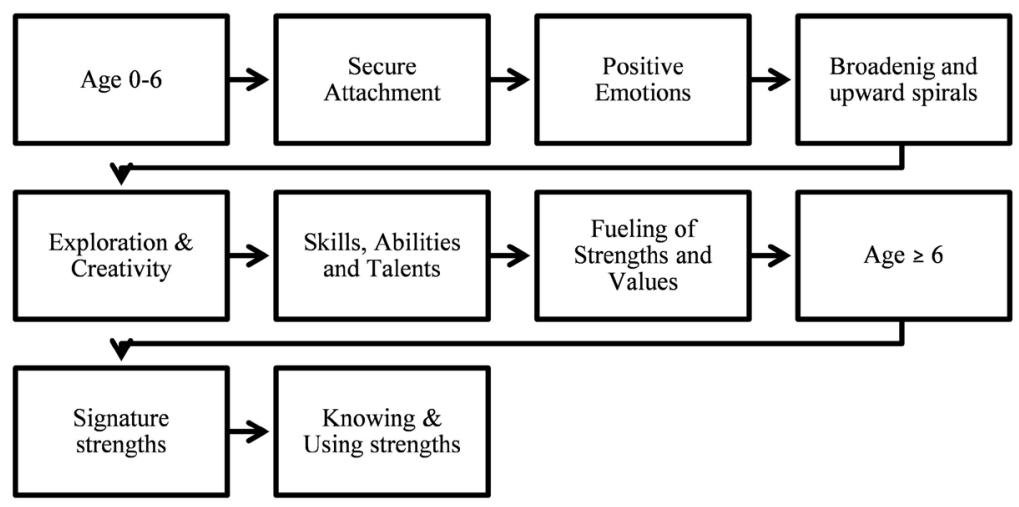

Figure 1. The proposed model of positive psychology parenting as defined by Seligman (2002). Source: Kyriazos \& Stalikas, 2018a.

1) Until the age of six, parenting is primarily oriented on the increase of a child's positive emotions, by showing abundant and unconditional love and acceptance.

2) Then positive emotions through their broadening effect (Fredrickson, 1998, 2001) boost exploration, creativity, and resourcefulness. This function has secure attachment as a prerequisite (Bowlby, 1969, 1973; Ainsworth et al., 1978).

3) Through exploration and creativity skills, abilities gradually emerge, eventually generating more positive emotions (i.e. an upward spiral; Fredrickson, 1998, 2001).

4) This recurrent process of acquiring mastery nurtures strengths and values that appear along the way. To this end, when a new character strength or value appears, parents should praise, name and encourage the child (positive reinforcement). This process is generally more effective if parents act also as a role model (Bandura, 1977; Huta, 2012).

5) With positive reinforcement, strengths become a potential source of positive emotions for the child (love, support, interest, or praise). Consequently, in an attempt to receive more positive emotions, the child will eventually use the strength again. During this recurring process, some attempts will be more successful than others.

6) Eventually, a child will abandon strengths that triggered a failure and will repeat those triggering successful attempts. Typically, by the age of six, a child will start using some of the successful strengths more often than others. These are signature strengths candidates.

7) Finally, certain strengths and values will consistently be repeated more frequently and successfully than others. These will probably be the signature strengths of the child.

8) Parents should build the child's education, skills, activities and ideally future career around his/her signature strengths. In this way, the chances of achieving long-lasting, eudemonic well-being are higher.

9) All along this process, if parents offer an abundance of positive emotions, they fuel the development of character strengths in their child. At the same time, 
they boost their own flourishing.

Preconditions for the Positive Psychology parenting model implementation

Nevertheless, for the above parenting model to take place, basic parenting tasks must be effectively carried out. These parenting tasks are (Bradley \& Caldwell, 1995; Bradley, 2002): 1) sustenance (survival, safety, and basic biological needs satisfaction), 2) cognitive and socioemotional stimulation, 3) support, 4) structure, and 5) surveillance. Sustenance, stimulation and support stem from basic needs postulated by Maslow's Hierarchy of needs (1975), as commented by Bradley (2002) (see also Ford \& Lerner, 1992). Structure and surveillance help parents to meet the child's needs contingently (Bradley, 2002).

Crucially, the well-being literature (Ryan \& Deci, 2000; Ryff, 2014; Seligman, 2011) also supports the assumption that the basic psychological needs-competence, autonomy, and relatedness-must be supported to achieve overall wellbeing (Self-determination theory, Ryan \& Deci, 2000; see also Wehmeyer \& Little, 2009; Boniwell, 2012). See Table 2 for a summary of the conditions of Positive Psychology Parenting.

Differences of Positive Psychology Parenting from the Positive Parenting "as usual" (Kyriazos \& Stalikas, 2018a)

In parenting literature, the term "positive" is simultaneously used by two parenting frameworks, in parallel with positive psychology parenting (Kyriazos \& Stalikas, 2018a): 1) positive discipline (Durrant, 2011; Nelsen, 2006) and 2) positive parenting (e.g. Sanders, 2012). Nevertheless, both positive discipline and positive parenting use the term "positive" to describes non-punitive parenting practices (Durrant, 2011; Sanders, 2012), or "firm and kind" parenting style (Nelsen, 2006). Crucially, within the positive psychology approach, the term "positive" refers to the broadening and building effect of positive emotions (Fredrickson, 1998, 2001). Apart from this difference, two additional differences between the two above theories from Positive psychology parenting are (Kyriazos \& Stalikas, 2018a): 1) the target population of the positive discipline and

Table 2. Conditions for positive psychology parenting to potentially come about.

\begin{tabular}{|c|c|}
\hline $\begin{array}{l}\text { Meeting necessary conditions } \\
\text { for Positive Psychology Parenting }\end{array}$ & $\begin{array}{l}\text { Meeting sufficient conditions for } \\
\text { Positive Psychology Parenting }\end{array}$ \\
\hline $\begin{array}{l}\text { Effectiveness in the following parental tasks: } \\
\text { - } \quad \text { Sustainability (survival and biological } \\
\text { integrity) } \\
\text { - } \quad \text { Secure Environment } \\
\text { - } \quad \text { Surveillance } \\
\text { - } \quad \text { Stimulation (cognitive \& social-emotional) } \\
\text { - } \quad \text { Support } \\
\text { - } \quad \text { Structure } \\
\text { - } \quad \text { Satisfactory marital relationship } \\
\text { (Bradley \& Caldwell, 1995; Bradley, 2002; } \\
\text { Maslow, 1975; Belsky, 1984; } \\
\text { Seligman, 2002) }\end{array}$ & $\begin{array}{l}\text { Effectiveness both in prerequisites and } \\
\text { in the following practices (Seligman, 2002): } \\
\text { - } \quad \text { Abundant and unconditional positive } \\
\text { emotions } \\
\text { - Identification of Strengths } \\
\text { - } \quad \text { Nuntification of Values } \\
\text { - } \quad \text { Nurturing Values } \\
\text { - } \quad \text { Finding child's signature strengths } \\
\text { - } \quad \text { Make sure child is using signature strengths } \\
\text { - } \quad \text { Building child's life around signature } \\
\text { strengths (play, marriage, carrier, } \\
\text { community) }\end{array}$ \\
\hline
\end{tabular}

Kyriazos \& Stalikas, 2018a. 
positive parenting is mainly (but not exclusively) children of special challenges, 2) their purpose is mainly prevention and treatment. The differences are summarized in Table 3. Of course, this does not imply that the above theoretical frameworks less effective, they simply use a different perspective from positive psychology (Seligman \& Csikszentmihalyi, 2000). In sum, the differences are equivalent to the differences of "psychology as usual" (Seligman \& Pawelski, 2003) from positive psychology (see also Kyriazos \& Stalikas, 2018a).

\section{The Present study}

The purpose of this study is the development and validation of a self-report measure of Positive Psychology Parenting (NICOMACHUS-Positive Parenting, NPP), based on the model postulated by Seligman (2002).

\section{Study 1: Test Development \& Pilot Testing}

The purpose of this study was: 1) to develop an item pool, 2) to carry out item analysis and Principle Components Analysis (PCA) in the final pool after pilot-testing it $(N=190)$.

\section{Study 1 Method \\ Participants}

The sample comprised by 190 parents from Greece (61\% females) with at least one child aged 7 - 13 years, raising 1 - 3 children per family. Most parents (70\%) were $>40$ years old, $28 \%$ were $26-40$ years old and $2 \%<25$ years old. The $4 / 5$ of the parents were married (80\%), 13\% endorsed "Other" and 7\% were living together with their partner. Most pants had a B.A. or higher (72\%), $24 \%$ had finished high school, and $4 \%$ junior high school or lower. Almost half of the sample $(49 \%)$ had an annual family income from $20.001 €-50.000 €, 29 \%$ from $10.001 €-20.000 €, 12 \%<10.000 €$ and $10 \%$ from $50.001 €-100.000 €$. Two of the parents had a child with a serious health problem, and one parent was caring for a child with special needs. Almost all of them (99\%) had a Greek nationality.

\section{Measures}

\section{Nicomachus-Positive Parenting (NPP)}

Table 3. Comparison of positive discipline, positive parenting and positive psychology parenting.

\begin{tabular}{|c|c|c|c|}
\hline & Positive Discipline & Positive Parenting & Positive Psychology Parenting \\
\hline Goal & Prevention \& Treatment & Prevention \& Treatment & Flourishing \\
\hline Jahoda (1958) model goal & $\begin{array}{l}\text { Move from }-2 \text { to zero } \\
\text { (no mental disease) }\end{array}$ & $\begin{array}{l}\text { Move from }-2 \text { to zero } \\
\text { (no mental disease) }\end{array}$ & $\begin{array}{l}\text { Move from } 0 \text { to as } \\
\text { high as possible }\end{array}$ \\
\hline Target Group & Cases with special challenges & Special \& General population & General population \\
\hline Family level impact & No unpleasant parent-child interactions & $\begin{array}{l}\text { Low-conflict } \\
\text { family environment }\end{array}$ & $\begin{array}{l}\text { Good/meaningful life } \\
\text { for the whole family }\end{array}$ \\
\hline \multirow[t]{2}{*}{ "Positive" means } & $\begin{array}{l}\text { Non-violent, non-punitive parenting } \\
\text { or Kind \& Firm parenting }\end{array}$ & $\begin{array}{c}\text { Non-violent, } \\
\text { non-maltreating parenting }\end{array}$ & $\begin{array}{l}\text { Positive emotions and their } \\
\text { Broadening and building effect } \\
\text { proposed by Fredrickson (2001) }\end{array}$ \\
\hline & (Durrant, 2011; Nelsen, 2006) & (Sanders, 2012) & (Seligman, 2002) \\
\hline
\end{tabular}

Source: Kyriazos \& Stalikas, 2018a. 
The final Pool of the Nicomachus-Positive Parenting (NPP) was used (114 items). The final pool emerged from an iterative process of discarding items, from an initial pool of 527 items. All items were developed for parents caring for children 7 - 13 years, and they were designed for a 5-point Likert scale $(1=\mathrm{Ab}$ solutely Untrue, 2 = Mostly Untrue, 3 = Can't Say True or Untrue, $4=$ Mostly True, $5=$ Absolutely True). The questionnaire is available in Appendix.

\section{The process of pool reduction}

Specifically, based on the Positive Parenting Model (Seligman, 2002) described in the Introduction section an initial item pool was created by 1) pulling items from several existing parenting scales (265 items) or items from positive psychology scales, adaptable for parenting (120 items); 2) translating descriptive statements contained in the Authentic Happiness (Seligman, 2002) into items (45 items); 3) writing items based on core premises of positive psychology (22 items); 4) adapting for parenting 75 items from the Values in Action Inventory of Strengths for Youth (VIA Youth, Peterson \& Seligman, 2004; Park \& Peterson, 2006).

This initial pool (527 items) was examined more closely. After (1) writing additional items from descriptive statements in Authentic Happiness (2002) and (2) removing similar, redundant, ambiguous, irrelevant and poorly worded items, a 258 -item pool was drafted (258 items). All items were arranged in two major categories with several sub-categories: 1) Meeting necessary conditions for Positive Psychology Parenting and 2) Meeting sufficient conditions for Positive Psychology Parenting (see Introduction and Kyriazos \& Stalikas, 2018a for a more elaborate discussion). The item distribution of this 258 -item pool is presented in Table 4.

Subsequently, experts with a Phd (1 female, 2 males) specialized in positive psychology (1 expert), or psychology and pedagogics (2 experts) reviewed the 258-item pool to evaluate content validity. For this purpose, they initially received a definition of the positive psychology parenting and a description of the

Table 4. Item allocation of the pool before reviewing by expert panel and focus group (258-item pool).

\begin{tabular}{|c|c|c|}
\hline N. of Items & Item Source & Item Category \\
\hline 81 & $\begin{array}{l}\text { Adaption in Greek from other } \\
\text { parenting questionnaires }\end{array}$ & $\begin{array}{l}\text { Meeting Necessary conditions } \\
\text { for Positive Psychology } \\
\text { Parenting }\end{array}$ \\
\hline 34 & $\begin{array}{c}\text { Adjusted for parenting from } \\
\text { positive psychology questionnaires }\end{array}$ & \\
\hline 68 & 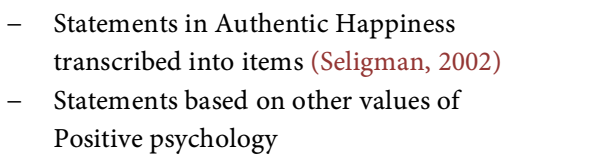 & $\begin{array}{l}\text { Meeting Sufficient Conditions } \\
\text { for Positive Psychology } \\
\text { Parenting }\end{array}$ \\
\hline 75 & $\begin{array}{l}\text { Adjusted for parenting from Values in Action } \\
\text { Inventory of Strengths for Youth (VIA-Youth, } \\
\text { Park \& Peterson, 2006; Peterson \& Seligman, 2004) }\end{array}$ & \\
\hline 258 & \multicolumn{2}{|c|}{ Items in the Reduced pool in total } \\
\hline
\end{tabular}


model proposed (Seligman, 2002, see Introduction section) along with the 258-item pool (listing item, item source and item dimension). Experts offered feedback on the following: 1) relevancy of each item on a relevancy scale ( $1=$ not at all relevant, 2 = probably relevant, $3=$ relevant, $4=$ extremely relevant); 2 ) clarity of each item on a clarity scale $(1=$ not at all clear, $2=$ probably clear, $3=$ clear, 4 = extremely clear); 3 ) omitted dimensions of positive parenting with narrative comments for each item, if necessary.

Then a focus group with parents was held ( $N=10,4$ males, 6 females) to evaluate the face validity of the 258-item pool in non-experts of the target population. The focus group initially received a simplified definition of the positive psychology parenting (see Introduction section, Seligman, 2002) and the 258-item pool (listing item and item dimension). Then, focus group participants were asked to rate items over two scales: 1$)$ A usefulness scale ( $1=$ not at all useful, 2 = probably useful, 3 = useful, 4 = extremely useful) was employed, 2) a clarity scale $(1=$ not at all clear, $2=$ probably clear, $3=$ clear, $4=$ extremely clear). A series of probes followed to get participants discuss the items. Probes included: 1) Did you understand the questions? 2) What in your own words does this question mean to you? (when some item was referenced); 3) Was there anything important left out? (Oremus et al., 2005; Willis, 2005; cited in Morton, Barling, Rhodes, Mâsse, Zumbo, \& Beauchamp, 2011). All comments were listed. Based on expert panel and focus group recommendations, an item was added about positive role-modeling (Bandura, 1977; Huta, 2012).

A final pool was drafted by keeping items rated both by an expert panel and focus group as 3 (useful/clear/relevant) or 4 (extremely useful/clear/relevant). Regarding scaling, items were rated on a 5-point Likert scale, ( $1=$ Absolutely Untrue, 2 = Mostly Untrue, 3 = Can't Say True or Untrue, $4=$ Mostly True, $5=$ Absolutely True), with anchors appearing only on the first and last point following OECD (2013) guidelines. However, each anchor was described in the initial instructions. All items rated the positivity of the parenting role (e.g. I make sure my child is in a good mood, even when something is going wrong), with no reverse-scored items. The final pool (114 items) was reexamined by the positive psychology expert and two parents to check if scale anchors and instructions were clear before pilot-testing it (see Results section). The item distribution of the final pool is shown in Table 5. See the iterative item reduction process in Figure 2.

\section{Procedure}

The data collection process was carried out electronically. Psychology students assisted the data collection. Specifically, 20 psychology students sent a link to 8 10 parents $(M=9.5)$, involving them in the study, after a short period of pilot testing the digital test battery. Eligibility criterion for participants was to have at least a child aged 7 - 13 years. All the parents recruited by the students were presented with a welcoming covering memo and a description of the study, followed by an inform consent. Then they specified a personal code for easy data retrieval and removal in case of a withdrawal and they completed the final pool 
Table 5. Description of items in the final pool (after expert panel review and focus group). This pool was pilot-tested.

\begin{tabular}{|c|c|c|c|}
\hline N. of Items & Item Source & Item Category & Item Sub-category \\
\hline 50 & $\begin{array}{l}\text { Translation in Greek and adaption from } \\
\text { other parenting resources ( } 6 \text { questionnaires } \\
\text { and } 1 \text { parenting program })^{*}\end{array}$ & $\begin{array}{ll}\text { - } & \text { Meeting necessary conditions for } \\
& \text { Positive Psychology Parenting \& } \\
\text { - } & \text { Meeting sufficient Conditions for } \\
& \text { Positive Psychology Parenting }\end{array}$ & $\begin{array}{l}\text { Basic needs, Child development, } \\
\text { Structure, Affection, } \\
\text { Communication, Realistic } \\
\text { Expectations from the child etc. }\end{array}$ \\
\hline 45 & $\begin{array}{l}\text { Adjusted for parenting from Values in Action } \\
\text { Inventory of Strengths for Youth (VIA-Youth, } \\
\text { Park \& Peterson, 2006; Peterson \& Seligman, 2004) }\end{array}$ & $\begin{array}{l}\text { Meeting sufficient conditions for } \\
\text { Positive Psychology Parenting }\end{array}$ & $\begin{array}{l}\text { Cultivating VIA Strengths and } \\
\text { Values (Transcendence, Courage, } \\
\text { Wisdom, Justice, Humanity, } \\
\text { Temperance }\end{array}$ \\
\hline 19 & $\begin{array}{l}\text { - } \text { Statements in Authentic Happiness transcribed } \\
\text { into items (Seligman, 2002) } \\
\text { - } \quad \text { Statements based on other values of } \\
\text { Positive psychology (e.g. Huta, 2012) }\end{array}$ & $\begin{array}{l}\text { Meeting sufficient conditions for } \\
\text { Positive Psychology Parenting }\end{array}$ & $\begin{array}{l}\text { Nurturing Positive Emotions, } \\
\text { Identifying Strengths, Boosting } \\
\text { Strengths, Satisfaction from } \\
\text { Parental Role etc. }\end{array}$ \\
\hline Totals & 114 Items in the Final Pool & 2 major categories & 46 Sub-categories \\
\hline
\end{tabular}

*Parenting Concerns Questionnaire (Sheppard, 2010); BASC-3 Parenting Relationship Questionnaire Sample Report (PsychCorp, 2015); Parenting Styles and Dimensions Questionnaire (Robinson et al., 1995); Alabama Parenting Questionnaire (Frick, 1991); Perceptions of Parents Questionnaire (Pasquali et al., 2012); Comprehensive Early Childhood Parenting Questionnaire (Verhoeven et al., 2017); Triple P parenting Program Principles (Triple-P International, 2014). ${ }^{*}$ PERMA Model (Seligman, 2011), role-modeling and parenting styles (Huta, 2012).

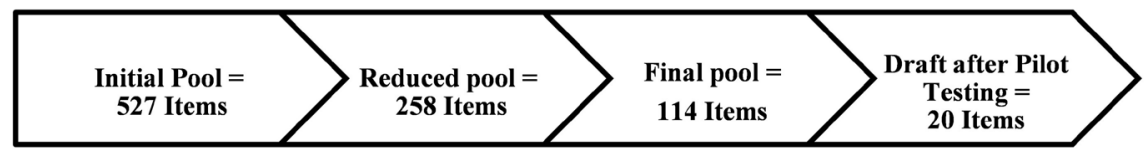

Figure 2. The iterative item reduction process from the initial pool to the final pool.

of NICOMACHUS. All the fields of the test battery were set as required. Students received extra credit for carrying out the recruitment process.

\section{Research Design}

After the theoretical model of the questionnaire has been established (see Introduction), the test development process described Study 1 is shown in Table 6.

Google Forms ${ }^{\circledast}$ hosted the electronic test battery. Data were analyzed with $\mathrm{R}$ software (R Development Core Team, 2019) with "psych" V1.8.12 (Revelle, 2019) package installed.

\section{Study 1 Results}

In order to eliminate non-response, all the fields of the digital form were set as "required". Therefore, the dataset had no missing values.

\section{Item analysis}

Items with the following properties were eliminated (Singh et al., 2016): $M<2$ and $>4$ (Jang \& Roussos, 2007), SD $<1$ (Jackson, 1970), Skewness $>|2|$ and Kurtosis $>|7|$ (Curran et al., 1996), ITC <.25 (Likert, 1932) or <.30 (Field, 2005). To ensure items were representing adequately the proposed theoretical model, items were subsequently reviewed and $M$ and $S D$ criteria were loosened for some items $(M \geq 4.4$ and $S D \leq 0.8)$. In total, from this item reduction process, 94 items were eliminated, resulting in a pilot version of 20 items, subsequently going through a Principal Components Analysis (PCA).

\section{Principal Components Analysis (PCA)}


Table 6. The test development process described in Study 1.

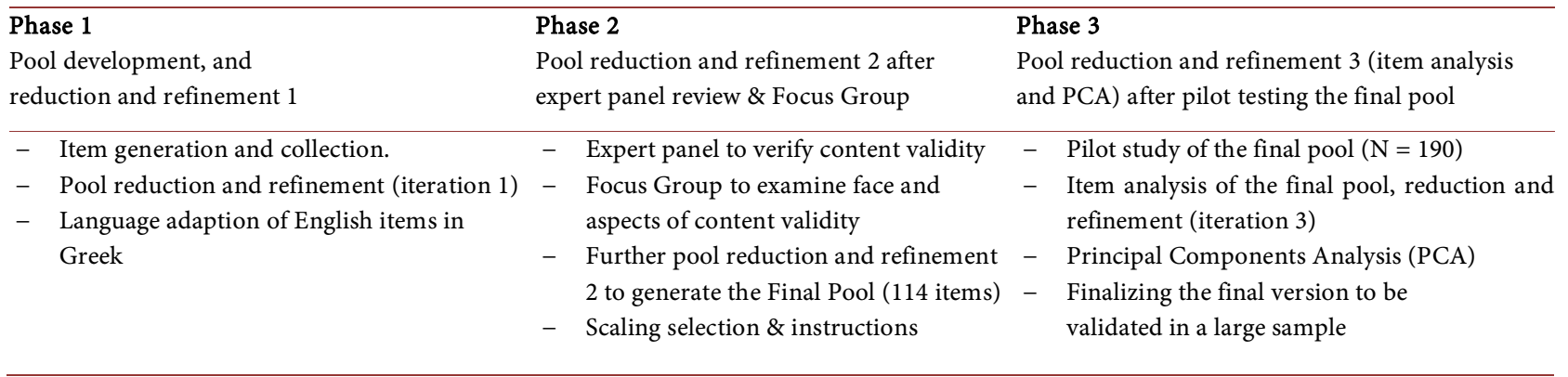

The purpose of the PCA was mainly to examine total explained variance and not to conclude about the structure (Singh et al., 2016). Kaiser-Meyer-Olkin measure of sampling adequacy (Kaiser, 1974) was .902, and Bartlett's test of sphericity (Bartlett, 1954) was significant, $\chi^{2}(190)=2324.82, p<.01$. Subsequently, PCA was carried out with oblique rotation, keeping all 20 items.

Initially, the correlation matrix was evaluated. All the 20 items correlated $\geq .30$ with at least a second item and no item had a negative value. The total variance explained by the 4 extracted components was $66.84 \%$. The inter-correlations of the 4 components ranged from .45 (component 2 with 4) to .50 (component 1 with 4). Internal consistency reliability was $\alpha=.91$.

\section{Study 1 Discussion}

The purpose of Study 1 was to describe the item generation, pool reduction, refinement, and piloting following the model operationalization (Seligman, 2002; Kyrazos \& Stalikas, 2018a), summarized in the Introduction section.

At first, an initial pool was established from: 1) existing scales with similar dimensions to the theoretical model of positive psychology parenting (Seligman, 2002, Kyrazos \& Stalikas, 2018a), 2) scales of positive psychology adaptable for parenting, 3) Transcribing Authentic Happiness (Seligman, 2002) content into items. This initial pool went through a refinement process and was reduced in about half. All items in English were adapted in Greek. Then to establish content validity it was reviewed by an expert panel. To establish face validity, a focus group was held. Half of the items were discarded based of the assessment of experts and the target population. The final pool was drafted with the remaining items. This final pool subsequently went through pilot testing with the purpose of item analysis and PCA and final refinement of the items.

Items were screened for extreme response bias. Thus, items deviating normality were rejected (Jang \& Roussos, 2007; Curran et al., 1996; Finney \& DiStefano, 2006; Barry \& Finney 2008 as reported by Singh et al., 2016) and items with low standard deviations were also rejected (Jackson, 1970). However, these criteria were loosened for certain items because: 1) they were considered important for the dimensions of the theoretical model, 2) this was a more conservative strategy, taking into consideration the sample size restrictions of the pilot study. After this reductive process, a 20 -item version of NICOMACHUS emerged with excellent reliability. 
The 20 items subsequently went through a PCA: 1) to examine percent variance explained (Singh et al., 2016), and 2) to organize more effectively the forthcoming validation research (Barker et al., 2016). However, no decisions were made on the factor structure. KMO was above .90 and Bartlett test was significant. After examination of the correlation matrix, the correlations ranged within acceptable limits and there were no negative values indicating a homogenous dataset (DeVellis, 2017). The pilot testing version contained 20 items in 4 components, explaining more than two thirds of the variance with excellent internal consistency reliability. Therefore, no further refinements followed. Henceforward, this version will be referred to as NICOMACHUS (NPP).

The next step is to validate the newly developed NICOMACHUS in a large scale study (Study 2).

\section{Study 2: Evidencing Construct Validity}

The purpose of this study was: 1) to establish construct the validity with EFA and CFA in a large sample; 2) to evaluate measurement invariance across child gender; 3) to evaluate internal consistency reliability and factor-based reliability; 4) to examine model-based convergent validity; 5) to establish the convergent and discriminant validity with other parenting measures and 6) to calculate normative data for the newly developed NICOMACHUS.

\section{Study 2 Method \\ Participants}

The sample involved 621 Greek parents (75\% of females), having at least one child from 7 to 13 years ( $M=10.23$ years, $\mathrm{SD}=2.11,54 \%$ females). The parents were $72 \%$ biological mothers, $24 \%$ biological fathers, and $4 \%$ endorsed “other". Per family there were either $1(32 \%), 2(48 \%), 3$ (15\%) or more $(5 \%)$ children. The majority of the parents (96\%) were living in the same house with the child they completed the questionnaire for., and $96 \%$ of them cared for a child with no special needs (biological, mental or other). More than half of them (54\%) were from 41 - 50 years, $28 \%$ from 31 - 40 years, 10\% from 51 - 60, 7\% from 21-30 and $1 \%$ were over 60 years old. Less than half of the participants (39\%) had a B.A. or higher $(20 \%)$, or they had finished high-school $(36 \%)$ or lower $(5 \%)$. The majority of the parents were working (84\%), and had a Greek nationality (99\%). Most parents (38\%) had an annual income between 10,001 and 20,000€ or lower (21\%) while $25 \%$ had an income between 20,001 and $30,000 €$ or higher (16\%).

\section{Measures}

\section{Nicomachus-Positive Parenting (NPP)}

This is the under validation questionnaire that emerged from Study 1, measuring Positive Psychology Parenting. The measure contains 20 items rated on a 5 point Likert scale ( $1=$ Absolutely Untrue, $2=$ Mostly Untrue, 3 = Can't Say True or Untrue, $4=$ Mostly True, $5=$ Absolutely True). All items are developed for children from 7 - 13 years. There are no reverse-scored items. The highest the score the highest the perceived positive psychology parenting. Score is rang- 
ing from a minimum of 1 to a maximum of 5 . The questionnaire is available in Appendix.

Alabama Parenting Questionnaire-Short Form (APQ-9, Elgar et al., 2007)

APQ-9 is the shortest version of the original APQ-42 (Frick, 1991; Shelton et al., 1996; Frick et al., 1999) containing nine items (e.g. You praise your child if he/she behaves well). APQ evaluates parenting practices correlated with child disruptive behaviors (Shelton et al., 1996). Items are rated on a 5-point scale ( $1=$ never to $5=$ always). Higher scores indicate a higher frequency of the parenting practice measured. Items are tapping three factors (Positive Parenting, Inconsistent Discipline, Poor Supervision) with 3 items each. A CFA suggested the 3 -factor APQ structure is tenable, $\chi^{2}(24)=44.10, \chi^{2} / \mathrm{df}=1.84$, RMSEA $=.044$, $\mathrm{CFI}=.951, \mathrm{TLI}=.926, \mathrm{SRMR}=.043$ (Kyriazos \& Stalikas, 2019a). The internal consistency reliability in the current study was $\alpha=.63$ (Positive Parenting), $\alpha$ $=.68$ (Inconsistent Discipline), $\alpha=.61$ (Poor Supervision). Elgar et al. (2007) reported an internal consistency, $\alpha=.59$ to .84 and $\alpha=.57$ to .62 in two validating studies.

Parenting Behaviours and Dimensions Questionnaire (PBDQ; Reid, Roberts, Roberts, \& Piek, 2015)

This relatively newly developed parenting measure contains 33 items of parenting behavior on six factors, i.e. Emotional Warmth (6 items), Punitive Discipline (5 items), Autonomy Support (5 items), Permissive Discipline (6 items), Anxious Intrusiveness (6 items) and Democratic Discipline (5 items). The items (e.g. I recognize my child's strengths and talents) are rated on a 6-point scale (from $1=$ never to $6=$ always). Possible scores range from 1 (lowest possible) to 6 (highest possible). A CFA confirmed this 6 -factor structure with a good fit, $\chi^{2}(465)=826.86, \chi^{2} / \mathrm{df}=1.78, \mathrm{RMSEA}=.042, \mathrm{CFI}=.922, \mathrm{TLI}=.912, \mathrm{SRMR}$ $=.071$ (Kyriazos \& Stalikas, 2019b). For this dataset internal consistency reliability per factor was $\alpha=.85$ (Emotional Warmth), $\alpha=.82$ (Punitive Discipline), $\alpha$ $=.77$ (Anxious Intrusiveness), $\alpha=.79$ (Autonomy Support), $\alpha=.69$ (Permissive Discipline), $\alpha=.76$ (Democratic Discipline). Similarly, PBDQ designers reported alpha coefficients from .66 to .83 (Reid et al., 2015).

Kansas Parental Satisfaction Scale (KPSS, James, Schumm, Kennedy, Grigsby, Shectman, \& Nichols, 1985).

KPSS is a 3-item scale of parental satisfaction. The items are rated on a 7-point Likert scale ( $1=$ extremely dissatisfied, $7=$ extremely satisfied). The score ranges from 3 (minimum parental satisfaction) to 21 (maximum parental satisfaction). To test this structure in the current ample, an EFA was carried out. Kaiser-Meyer-Olkin measure of sampling adequacy (Kaiser, 1970, 1974) was .71, and Bartlett's test of sphericity (Bartlett, 1954) was significant $\left(\chi^{2}(3)=687.06, p\right.$ $<.001$ ). A single parent satisfaction factor emerged (PAF extraction, Oblimin rotation), total variance explained $61.28 \%$. Factor loadings were $.80, .69$ and .85 and communalities were .64, .48, .72 (Kyriazos \& Stalikas, 2019c). The internal consistency reliability of this solution was $\alpha=.82$. The reported internal consis- 
tency reliability for KPSS ranged from .78 to .95 (Nitsch et al., 2015).

Parent Behavior Inventory (PBI; Lovejoy, Weis, O’Hare, \& Rubin, 1999)

PBI is measuring parenting behaviors. The 20 items (e.g. I thank or praise my child) are rated on a 6-point scale, from $0=$ not at all true/ $I$ do not do this to $5=$ very truel I often do this. Higher scores indicate a higher frequency of the measured behavior. Items tap two factors, the hostile/coercive factor, and the supportive/engaged factor. A CFA confirmed this dual structure in the current sample, $\chi^{2}(159)=322.77, \chi^{2} / \mathrm{df}=2.03, \mathrm{RMSEA}=.049, \mathrm{CFI}=.925, \mathrm{TLI}=.911$, SRMR $=.069$ (Kyriazos \& Stalikas, 2019d). The internal consistency reliability of the CFA solution was $\alpha=.86$ (supportive/engaged factor), and $\alpha=.81$ (hostile/coercive factor). The developers (Lovejoy et al., 1999) reported an internal consistency of $\alpha=.83$ (supportive/engaged factor) and $\alpha=.81$ (hostile/coercive factor).

Parent Concerns Questionnaire (PCQ; Sheppard, 2010)

PCQ is a measure of child developmental or parental problems (Sheppard, 2010). PCQ has 37 items arranged on three domains (parenting capacity, child development, family/environmental factors). Each item (e.g. I feel our/my physical care of my children is not as good as it should be) is evaluated on a 3-point scale $(0=$ not present, $1=$ present, $2=$ severe $)$, producing an aggregated score. Intervention by professionals may be necessary for problems rated as "severe". In the current study this 3-dimensional theoretical structure was verified with a CFA, $\chi 2(30)=57.76, \chi 2 / \mathrm{df}=1.93, \mathrm{RMSEA}=.046, \mathrm{CFI}=.965, \mathrm{TLI}=.947, \mathrm{SRMR}$ $=.041$ (Kyriazos \& Stalikas, 2019e). Factor 1 (Child development problems) contained items 24, 25, 29, Factor 2 (Parenting Capacity problems) items 34, 35, 36, and Factor 3 (family/environmental problems) contained items 4, 10, 11, 12 (Kyriazos \& Stalikas, 2019e). This 10-item PCQ version had alphas of .76 (Child Development Problems), .71 (Parenting Capacity problems) and .77 (Family/Environmental Problems). The test developer (Sheppard, 2010) reported internal consistency reliability of $\alpha=.89, .79$, and .73 for the Child Development problems, Parenting Capacity problems and Family/Environmental problems respectively (for the full 37-item version).

Parental Stress Scale (PSS; Berry \& Jones, 1995)

PSS is a measure of perceived parental stress with 20 items (e.g. The major source of stress in my life is my child) rated on a 5-point Likert scale ( $1=$ "strongly disagree" to 5 = "strongly agree"). Higher scores suggest higher parental stress. Items could be generally organized in two major domains (positive parenting and stressful parenting). Berry and Jones (1995: p. 470) found a 4-factor structure to "support the dichotomy of the parenting experience and the theoretical bases of the Parental Stress Scale". In this study this theoretical dichotomy of the PSS was confirmed with a CFA, $\chi^{2}(72)=148.86, \chi^{2} / \mathrm{df}=2.07$, RMSEA $=.050$, CFI $=.951$, TLI $=.938$, SRMR $=.062($ Kyriazos \& Stalikas, 2019f). Factor 1 (Positive Parenting Themes) comprised items 1, 5, 6, 7, 8, 17, 18 and Factor 2 (Stressful Parenting Themes) comprised items 3, 4, 10, 11, 12, 15, 16. The internal consistency reliability of this dual model was $\alpha=.87$ (positive 
parenting themes, reversed scored) and $\alpha=.76$ (stressful parenting themes). Berry \& Jones (1995) reported an overall alpha coefficient of .83 .

\section{Procedure}

The procedure was similar to Study 1. In this study, 100 psychology students assisted in an online data collection, by recruiting at least 5 parents of children aged 7 - 13 years $(M=6.21)$. The test-battery had all fields set as "required".

\section{Research Design}

Table 7 present and overview of the analyses carried out in Study 2.

Google Forms ${ }^{\circledast}$ hosted the electronic test battery. Data were analyzed with $\mathrm{R}$ software (R Development Core Team, 2019). The following packages were installed: "haven" V 2.1.1 (Wickham, 2019a), "psych" V1.8.12 (Revelle, 2019), "lavaan” V0.6 - 4 (see Rosseel, 2012), “MVN” 5.7 (Korkmaz, 2019), “caret” v6.0 - 84 (Kuhn, 2019), "knitr" V1.23 (Xie, 2019), "dplyr" v0.7.8 (Wickham, 2019b), "tidyr" v0.8.3 (Wickham, 2019c), semPlot v1.1.1 (Epskamp, 2019), "semTools" v0.5-1 (Jorgensen, 2019).

\section{Study 2 Results}

The fields of the digital test-battery were set as "required", so data contained no missing values. Three out of 621 cases were outliers, $\chi^{2}[20]=45.31, p<.001$ (Mahalanobis distance, Mahalanobis, 1936). However, outliers were included in the sample because minor differences were observed when comparing findings with and without outliers. The sample $(N=621)$ was split in two random subsamples $\left(n_{\mathrm{EFA}}=187\right.$ and $\left.n_{\mathrm{CFA}}=434\right)$. The cases to measured variables ratio for

Table 7. Research analyses overview in study 2.

\begin{tabular}{|c|c|c|}
\hline Sequence & Analyses Carried out & Sample \\
\hline 1 & $\begin{array}{ll}\text { - } & \text { Sample Splitting } \\
\text { - } & \text { Data Cleaning (missing values and outliers) } \\
\text { - } & \text { Power Analysis (population RMSEA method, MacCallum, } \\
& \text { Browne, \& Sugawara, 1996) }\end{array}$ & $\begin{array}{l}\text { Total } \\
70 \%\end{array}$ \\
\hline 2 & $\begin{array}{ll}\text { - } & \text { Univariate Normality } \\
\text { - } & \text { Multivariate Normality with multiple tests }\end{array}$ & Total \\
\hline 3 & Exploratory Factor Analysis (EFA) to determine the structure & $30 \%$ \\
\hline 4 & Confirmatory Factor Analysis evaluating multiple models & $70 \%$ \\
\hline 5 & $\begin{array}{l}\text { - Internal Consistency Reliability using a coefficient (Cronbach, 1951) } \\
\text { _ Model-Based Reliability (Mair, 2018; Sha \& Ackerman, 2018) using } \\
\text { three } \omega \text { coefficients (Bollen, 1980; Bentler, 1972, 2009; McDonald, } \\
\text { 1999) } \\
\text { - Model Based Convergent Validity using Average Variance } \\
\text { Extracted (AVE; Fornell \& Larcker, 1981) }\end{array}$ & Total \\
\hline 6 & $\begin{array}{l}\text { Full measurement Invariance to the strict level across the child } \\
\text { gender the parents completed NICOMACHUS for. }\end{array}$ & Total \\
\hline 7 & $\begin{array}{l}\text { - Convergent/Discriminant Validity with } 6 \text { parenting measures } \\
\text { having } 13 \text { scales of positive and non-positive parenting }\end{array}$ & Total \\
\hline 8 & $\begin{array}{ll}- & \text { Descriptive Statistics } \\
\text { - } & \text { Standardization of NICOMACHUS/NPP and per factor }\end{array}$ & Total \\
\hline
\end{tabular}


$n_{\mathrm{EFA}}$ and $n_{\mathrm{CFA}}$ (Costello \& Osborne, 2005; Ullman, 2013) were 9:1 and 22:1 respectively.

The most complicated model tested was a 4-factor model with two error covariances. Power analysis for this model with the population RMSEA method (MacCallum, Browne, \& Sugawara, 1996; Hancock \& Freeman, 2001) suggested $N \geq 96$ cases $\left(\mathrm{RMSEA} 0=.05\right.$, RMSEA $=.08, \mathrm{df}_{\mathrm{M}}=162$, power $=.80, N=621$ ).

\section{Univariate and Multivariate Normality}

The Kolmogorov-Smirnov, Shapiro-Wilk, Shapiro-Francia and Anderson-Darlingall tests of univariate normality were statistically significant ( $p$ $<.001$ ) for all 20 Nicomachus measured variables (Table 8). The Mardia's multivariate kurtosis test (Mardia, 1970), Mardia's multivariate skewness test (Mardia, 1970), Henze-Zirkler's consistent test (Henze \& Zirkler, 1990), Doornik-Hansen omnibus test (Doornik \& Hansen, 2008), E-statistic and Roston test were significant, $p<.001$ (Table 8).

Table 8. Descriptive Statistics, univariate normality tests and multivariate normality tests for each NICOMACHUS measured variable in the total sample and subsamples.

\begin{tabular}{|c|c|c|c|c|c|c|c|c|c|c|}
\hline \multirow{2}{*}{$\begin{array}{l}\text { Measured } \\
\text { Variables }\end{array}$} & \multicolumn{4}{|c|}{ Descriptive Statistics $(N=621)$} & \multicolumn{6}{|c|}{ Univariate Normality Tests $(N=621)$} \\
\hline & $\begin{array}{c}\text { Mean } \\
(M)\end{array}$ & $\begin{array}{c}\text { St. Dev. } \\
(S D)\end{array}$ & Skew & Kurtosis & \multicolumn{2}{|c|}{ Kolmogorov-Smirnov } & Shapiro-Wilk & Shapiro-Francia & Ander & son-Darling \\
\hline ITEM 1 & 4.32 & .88 & -1.53 & 2.57 & \multicolumn{2}{|c|}{.30} & \multicolumn{2}{|r|}{.74} & & 59.95 \\
\hline ITEM 2 & 4.62 & .81 & -2.83 & 8.74 & \multicolumn{2}{|c|}{.42} & \multicolumn{2}{|r|}{.52} & & 116.42 \\
\hline ITEM 3 & 4.66 & .83 & -3.09 & 9.88 & \multicolumn{2}{|c|}{.45} & \multicolumn{2}{|r|}{.46} & & 136.85 \\
\hline ITEM 4 & 4.33 & .93 & -1.57 & 2.27 & \multicolumn{2}{|c|}{.32} & \multicolumn{2}{|r|}{.72} & & 65.94 \\
\hline ITEM 5 & 4.41 & .83 & -1.73 & 3.51 & \multicolumn{2}{|c|}{.32} & \multicolumn{2}{|r|}{.70} & & 68.78 \\
\hline ITEM 6 & 4.36 & .97 & -1.70 & 2.49 & \multicolumn{2}{|c|}{.35} & \multicolumn{2}{|r|}{.69} & & 76.64 \\
\hline ITEM 7 & 4.19 & .88 & -1.14 & 1.45 & \multicolumn{2}{|c|}{.25} & \multicolumn{2}{|r|}{.79} & & 47.11 \\
\hline ITEM 8 & 4.36 & .88 & -1.73 & 3.52 & \multicolumn{2}{|c|}{.31} & \multicolumn{2}{|r|}{.71} & & 64.55 \\
\hline ITEM 9 & 4.24 & .9 & -1.43 & 2.28 & \multicolumn{2}{|c|}{.26} & \multicolumn{2}{|r|}{.76} & & 53.36 \\
\hline ITEM 10 & 4.29 & .86 & -1.39 & 2.18 & \multicolumn{2}{|c|}{.28} & \multicolumn{2}{|r|}{.76} & & 56.08 \\
\hline ITEM 11 & 4.34 & .84 & -1.44 & 2.30 & \multicolumn{2}{|c|}{.31} & \multicolumn{2}{|r|}{.74} & & 6.75 \\
\hline ITEM 12 & 4.31 & .81 & -1.38 & 2.47 & \multicolumn{2}{|c|}{.27} & \multicolumn{2}{|r|}{.75} & & 56.48 \\
\hline ITEM 13 & 4.09 & .96 & -1.05 & .99 & & & .81 & .81 & & 41.96 \\
\hline ITEM 14 & 3.93 & 1.01 & -.87 & .39 & & & .84 & .85 & & 34.76 \\
\hline ITEM 15 & 3.99 & 1.2 & -1.17 & .45 & & & .78 & .78 & & 49.82 \\
\hline ITEM 16 & 4.18 & .99 & -1.36 & 1.63 & & & .77 & .77 & & 51.44 \\
\hline ITEM 17 & 4.17 & 1.16 & -1.44 & 1.19 & & & .72 & .73 & & 66.23 \\
\hline ITEM 18 & 3.91 & 1.15 & -.95 & .02 & & & .82 & .82 & & 4.72 \\
\hline ITEM 19 & 4.22 & 1.06 & -1.44 & 1.35 & & & .73 & .73 & & 64.40 \\
\hline ITEM 20 & 4.15 & 1.04 & -1.25 & 1.02 & & & .78 & .78 & & 51.87 \\
\hline & & & & & [ultivariate & rmality $\mathrm{Te}$ & & & & \\
\hline & Sample & & $\begin{array}{r}\mathrm{Ma} \\
\mathrm{S}\end{array}$ & & $\begin{array}{l}\text { Mardia's } \\
\text { kurtosis }\end{array}$ & Henze-Zir & Doorn & ik-Hansen & tatistic & Royston \\
\hline Total s & mple ( $\Lambda$ & $=621)$ & & .22 & 72.76 & 2.00 & & 21.80 & 71.70 & 2720.70 \\
\hline EFA subs & Imple ( $n$ & $\mathrm{~A}=187)$ & & 6.85 & 29.10 & 1.29 & & 64.88 & 5.16 & 1397.40 \\
\hline CFA subs & Imple ( $n$ & $\mathrm{~A}=434)$ & & .40 & 51.52 & 1.70 & & 366.81 & .512 & 2275.04 \\
\hline
\end{tabular}

Note. All univariate and multivariate normality tests were significant at $p<.001$ level. 


\section{Exploratory Factor Analysis $\left(n_{\mathrm{EFA}}=187\right)$}

The factorability of the correlation matrix was at first examined. NICOMACHUS inter-item correlations were $\geq .30$. Kaiser-Meyer-Olkin measure of sampling adequacy (Kaiser, 1970, 1974) was .91, and Bartlett's test of sphericity (Bartlett, 1954) was significant $\left(\chi^{2}(190)=2216.349, p<.01\right)$. The diagonals of the anti-image correlation matrix were $>.50$. Given the above factorability indications, EFA was carried out with all 20 NICOMACHUS items.

Factors were extracted with Principal Factor extraction with oblique rotation. Number of factors to retain was examined with the scree plot (Cattell, 1978), Parallel Analysis (PA; Horn, 1965), Minimum Average Partial Correlations (MAP; Velicer, 1976), and lowest possible Bayesian information criterion (BIC; Schwartz, 1978) and the goodness of model fit. The EFA goodness of model fit was evaluated with the Root Mean Square Error of Approximation (RMSEA; Steiger \& Lind, 1980), Root Mean Square of Residuals (RMSR), Comparative Fit Index (CFI; Bentler, 1990), Tucker-Lewis Index (TLI; Tucker \& Lewis, 1973) and Bayesian information criterion (BIC; Schwartz, 1978). Fit criteria (Hu \& Bentler, 1999; Browne \& Cudeck, 1993) were RMSEA $\leq .06$ [90\% Confidence Intervals $\leq .06$ ], RMSR $\leq .0448$ (Kelley's criterion; Kelley, 1935; Harman, 1962; Lorezo-Seva \& Ferrando, 2013) CFI and TLI $\geq .95$, and lowest possible BIC.

PA suggested four factors (Figure 3). The Velicer MAP achieved a minimum of 0.02 with 4 factors and BIC achieved a minimum of -373.58 with 4 factors. Considering the above findings, 4 factors were extracted (total explained variance $=66.35 \%$ ). The first factor explained $45.35 \%$ of the variance, the second $8.65 \%$, the third $6.5 \%$ and the four-factor $5.85 \%$ with communalities $>.47$. This 4-factor model had an acceptable fit, RMSR $=.030$, TLI $=.931$, RMSEA $=.078$ $[90 \% \mathrm{CI} .06, .087]$ and $\mathrm{BIC}=-373.53$.

Items 1 - 9 loaded on the first factor with loadings ranging from .50 to .82 . Items 10 - 14 loaded on the second factor with loadings from .46 to .76 . Items 15 - 17 loaded on the third factor with loadings ranging from .43 to .97 . Items 18 20 loaded on the fourth factor with loadings ranging from .54 to .78 . There were

Parallel Analysis Scree Plots

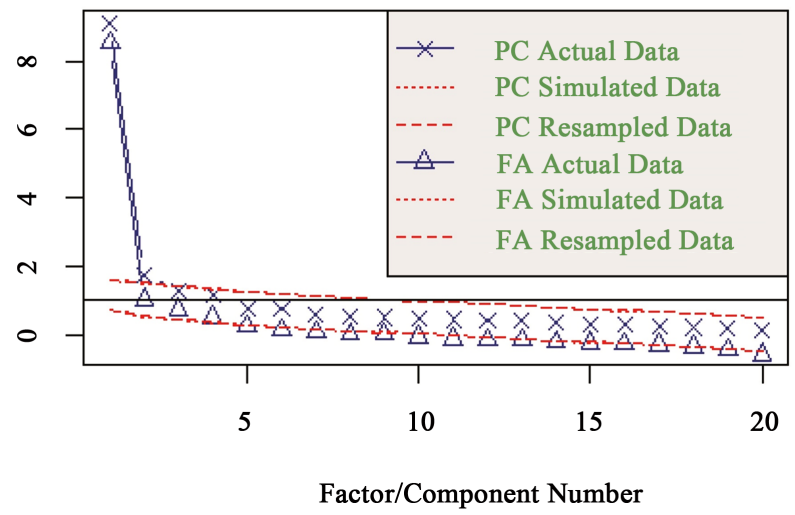

Figure 3. Scree plots of actual and simulated data in parallel analysis. 
no cross-loadings. After item inspection, the first factor was named Nurturing Values (NV), the second factor Strength Identification \& Boosting (SIB), the third-factor Parenting Context (PC), and the fourth factor was called Involvement (I). The range of the factor loadings in all four factors was from .43 to .97 . Factor inter-correlations ranged from .30 to .63 . Table 9 contains the factor loadings above .30 , communalities and factor inter-correlations (also presented in Figure 4).

Table 9. EFA factor loadings, communalities and factor inter-correlations of NICOMACHUS.

\begin{tabular}{|c|c|c|c|c|c|}
\hline \multirow{3}{*}{$\begin{array}{c}\left(n_{\mathrm{EFA}}=187\right) \\
\text { Measured Variables }\end{array}$} & \multicolumn{4}{|c|}{ NICOMACHUS Factors } & \multirow{3}{*}{ Communalities } \\
\hline & Factor 1 (PA1) & Factor 2 (PA3) & Factor 3 (PA2) & Factor 4 (PA4) & \\
\hline & $\mathrm{NV}$ & SIB & PC & I & \\
\hline ITEM 1 & .80 & - & - & - & .58 \\
\hline ITEM 2 & .79 & - & - & - & .71 \\
\hline ITEM 3 & .82 & - & - & - & .66 \\
\hline ITEM 4 & .69 & - & - & - & .49 \\
\hline ITEM 5 & .54 & - & - & - & .51 \\
\hline ITEM 6 & .50 & - & - & - & .52 \\
\hline ITEM 7 & .70 & - & - & - & .5 \\
\hline ITEM 8 & .66 & - & - & - & .66 \\
\hline ITEM 9 & .67 & - & - & - & .56 \\
\hline ITEM 10 & - & .61 & - & - & .59 \\
\hline ITEM 11 & - & .76 & - & - & 06 \\
\hline ITEM 12 & - & .71 & - & - & .59 \\
\hline ITEM 13 & - & .46 & - & - & .48 \\
\hline ITEM 14 & - & .53 & - & - & .47 \\
\hline ITEM 15 & - & - & .72 & - & .58 \\
\hline ITEM 16 & - & - & .43 & - & .51 \\
\hline ITEM 17 & - & - & .97 & - & .97 \\
\hline ITEM 18 & - & - & - & .69 & .48 \\
\hline ITEM 19 & - & - & - & .78 & .73 \\
\hline ITEM 20 & - & - & - & .54 & .58 \\
\hline \multicolumn{6}{|c|}{ NICOMACHUS Factor Inter-correlations } \\
\hline & Factor 1 (PA1) & Factor 2 (PA3) & Factor 3 (PA2) & Factor 4 (PA4) & \\
\hline & NV & SIB & PC & I & \\
\hline Factor 1-NV & - & & & & \\
\hline Factor 2-SIB & .63 & - & & & \\
\hline Factor 3-PC & .37 & .30 & - & & \\
\hline Factor 4-I & .49 & .46 & .35 & - & \\
\hline
\end{tabular}

Notes: NICOMACHUS Factors: NV = Nurturing Values, SIB = Strength Identification \& Boosting, PC = Parenting Context, I = Involvement. Extraction = Principal Factor $(\mathrm{fm}=$ "pa") with an oblique oblimin rotation (rotate = "oblimin"). Loadings $<.30$ were excluded. 


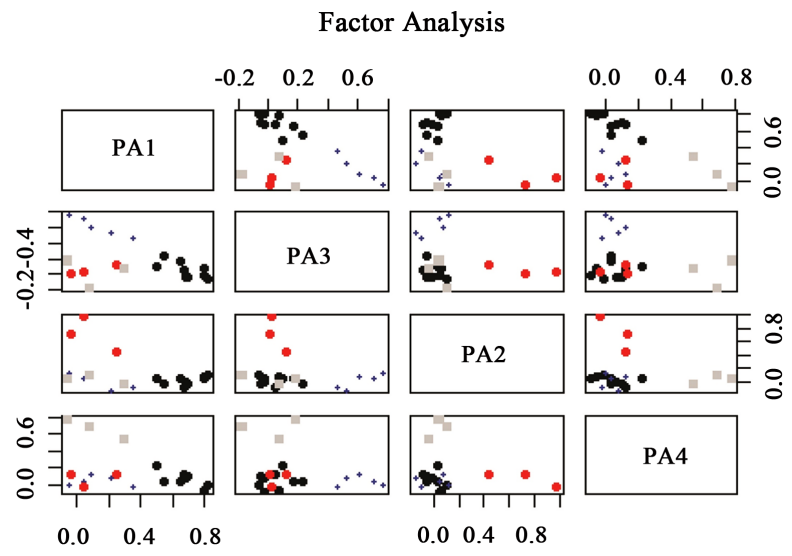

Figure 4. Factor loadings of each factor for the 4-factor model emerging from EFA.

\section{Confirmatory Factor Analysis $\left(n_{\mathrm{CFA}}=434\right)$}

The Robust Maximum Likelihood was used to estimate parameters (MLR; see Yuan \& Bentler, 2000). Goodness of fit was assessed with RMSEA $\leq 0.06$, RMSEA 90\% CI $\leq 0.06$, SRMR $\leq 0.08$, CFI $\geq 0.95$, TLI $\geq 0.95$ (Hu \& Bentler, 1999; Browne \& Cudeck, 1993; Brown, 2015), Chi-square/df ratio < 3 (see Kline, 2010, 2016) Akaike information criterion (AIC; Akaike, 1987) and BIC (the lower the better, Mair, 2018).

Four models were specified: 1) MODEL A was a single-factor model with all 20 NICOMACHUS items in one factor to test the maximum parsimony assumption (Brown, 2015); 2) MODEL B was a first-order, Independent Cluster CFA Model (ICM-CFA; Marsh et al., 2014, Howard et al., 2016) with two correlated factors. Factor 1 contained Items 1 - 14 and Factor 2 contained items 15 - 20;3) Model C was a first-order ICM-CFA model with four correlated factors. Factor 1 had items 1 - 9, Factor 2 items 10 - 14, Factor 3 items 15 - 17 and Factor 4 had items 18 - 20; 4) Model D was a variation of MODEL C with two error covariances added, i.e. in item 2 with item 3 and in item 13 with item 14.

Regarding the model fit, the assumption of maximum parsimony was rejected (MODEL A). The two-factor ICM-CFA model also had a poor fit (MODEL B). The 3-factor model (MODEL C) had a good fit, with all fit statistics, factor loadings and factor correlations within the acceptable levels. MODEL D had an even better fit with all fit indexes, and factor loadings factor loadings and factor correlations within and far above the expected limits. The fit statistics and the standardized loadings of all the models are presented in Table 10 and the path of MODEL C in Figure 5.

\section{Measurement Invariance}

The full measurement invariance was evaluated across the gender of the child to the strict level. The nested models were compared with $\Delta \mathrm{CFI} \leq .01$ (Cheung \& Rensvold, 2002; Chen, 2007) and $\triangle$ RMSEA $\leq .015$ (Chen, 2007).

The 4-factor model (MODEL C) was tested separately for each child-gender with a good fit both for girls $(N=337)$, and for boys $(N=284)$, see Table 11 . The nested models $(1-4)$ also fit the data well. The weak to configural model 
Table 10. Goodness of fit measures, factor Loadings and Inter-correlations for the NICOMACHUS Models specified in the CFA.

\begin{tabular}{|c|c|c|c|c|c|c|c|c|c|c|c|c|c|}
\hline \multirow{2}{*}{$\begin{array}{c}N=434 \\
\text { Model }\end{array}$} & \multicolumn{11}{|c|}{$\begin{array}{l}\text { RMSEA } \\
90 \% \mathrm{CI}\end{array}$} & \multirow{2}{*}{\multicolumn{2}{|c|}{$\begin{array}{cc}\text { Factor Loadings } & \begin{array}{c}\text { Factor } \\
\text { Inter-correlations }\end{array} \\
\text { Range }\end{array}$}} \\
\hline & $\chi^{2}$ & $\mathrm{Df}$ & $\chi^{2} / \mathrm{df}$ & CFI & TLI & RMSEA & Lower & Higher & SRMR & BIC & AIC & & \\
\hline $\begin{array}{l}\text { MODEL A } \\
\text { Single factor }\end{array}$ & 1115.73 & 170 & 6.56 & .817 & .795 & .095 & .090 & .099 & .071 & $28,432.86$ & $28,255.60$ & $.397-.836$ & - \\
\hline $\begin{array}{c}\text { MODEL B } \\
2 \text {-factors } \\
(\mathrm{F} 1+\mathrm{F} 2, \mathrm{~F} 3+\mathrm{F} 4)\end{array}$ & 975.15 & 169 & 5.77 & .844 & .824 & .088 & .083 & .092 & .063 & $28,232.88$ & $28,051.20$ & $\begin{array}{l}F 1+F 2.590-.844 \\
F 3+F 4.523-.714\end{array}$ & .789 \\
\hline $\begin{array}{l}\text { MODEL C } \\
\text { 4-factors }\end{array}$ & 466.36 & 164 & 2.84 & .941 & .932 & .054 & .049 & .060 & .060 & $27,578.38$ & $27,374.54$ & $\begin{array}{l}\text { F1 } .657-.858 \\
\text { F2 } .647-.801 \\
\text { F3 } .589-.894 \\
\text { F4 .581- } .812\end{array}$ & $\begin{array}{l}\text { F1 - F2 .813 } \\
\text { F1 - F3 .479 } \\
\text { F1 - F4 .714 } \\
\text { F2 - F3 .434 } \\
\text { F2 - F4 .674 } \\
\text { F3 - F4 .416 }\end{array}$ \\
\hline $\begin{array}{l}\text { MODEL D } \\
\text { 4-factors With } \\
\text { Cov. Errors }\end{array}$ & 324.61 & 162 & 2.00 & .969 & .963 & .040 & .035 & .046 & .058 & $27,405.61$ & $27,192.90$ & $\begin{array}{l}\text { F1 } .673-.828 \\
\text { F2 } .594-.816 \\
\text { F3 } .589-.894 \\
\text { F4 } .581-.813\end{array}$ & $\begin{array}{l}\text { F1 - F2 .814 } \\
\text { F1 - F3 .477 } \\
\text { F1 - F4 .721 } \\
\text { F2 - F3 .442 } \\
\text { F2 - F4 .681 } \\
\text { F3 - F4 .416 }\end{array}$ \\
\hline
\end{tabular}

Note. Estimator = MLR; Bold typeface indicates models with optimal fit.

Table 11. (a) Goodness-of-Fit measures for the Baseline model for testing measurement invariance across child gender; (b) Nested models Comparison to validate full measurement invariance across the child gender of the parents. (a) Baseline Model fit ( $N=621$, 337 girls \& 284 boys); (b) Nested models Comparison.

(a)

\begin{tabular}{|c|c|c|c|c|c|c|c|c|c|}
\hline \multirow{2}{*}{ Models } & \multirow{2}{*}{$\begin{array}{l}\text { Chi-Square } \\
\text { Value }\end{array}$} & \multirow{2}{*}{$\begin{array}{c}\text { Chi-Square } \\
\text { df }\end{array}$} & \multirow{2}{*}{ Chi-square/df } & \multirow{2}{*}{ CFI } & \multirow{2}{*}{ TLI } & \multirow{2}{*}{ RMSEA } & \multicolumn{2}{|c|}{ RMSEA CI 90\% } & \multirow{2}{*}{ SRMR } \\
\hline & & & & & & & Lower & Higher & \\
\hline $\begin{array}{c}\text { GIRLS MODEL } \\
\text { 4-factors correlated }\end{array}$ & 375.78 & 164 & 2.29 & .935 & 0.925 & .062 & .055 & .069 & .063 \\
\hline $\begin{array}{c}\text { BOYS MODEL } \\
\text { 4-factors correlated }\end{array}$ & 327.16 & 164 & 1.99 & .926 & 0.915 & .059 & .051 & .068 & .069 \\
\hline
\end{tabular}

(b)

\begin{tabular}{|c|c|c|c|c|c|c|c|}
\hline Models & Chi-Square & Df & CFI & RMSEA & Model comparison & $\Delta \mathrm{CFI}$ & $\triangle \mathrm{RMSEA}$ \\
\hline $\begin{array}{l}\text { Full Configural } \\
\text { invariance }\end{array}$ & 466.36 & 164 & .941 & .054 & - & - & - \\
\hline Full Weak invariance & 714.16 & 344 & .932 & .059 & Model 2 vs 1 & -.009 & .005 \\
\hline Full Strong invariance & 742.20 & 360 & .930 & .058 & Model 3 vs 2 & -.002 & -.001 \\
\hline Full Strict. invariance & 759.45 & 380 & .931 & .057 & Model 4 vs 3 & .001 & -.001 \\
\hline
\end{tabular}

Note Estimator $=$ MLR .

comparison, the strong to weak model comparison and the strict to strong model, comparison yielded $\triangle$ CFIs and $\triangle$ RMSEAs below the non-invariance cutoffs (Table 11). 


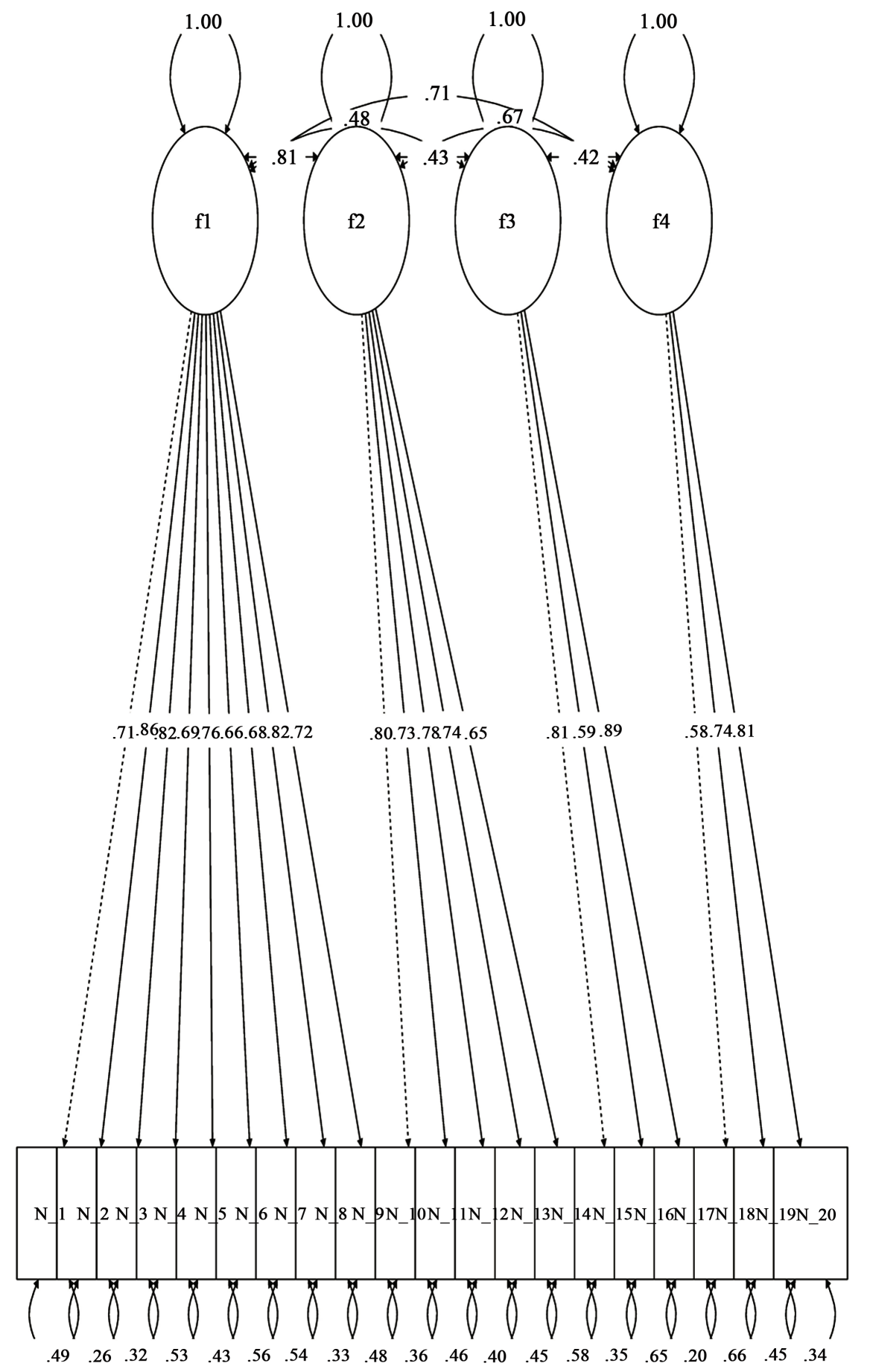

Figure 5. Path diagram of the four factor model with 4 correlated factors estimated in the $70 \%$ of the sample in study 2 .

\section{Internal Consistency Reliability, Model-Based Reliability, and Validity}

Generally, a value of Cronbach's alpha coefficient $\geq .70$ is generally considered acceptable and the same is true for Omega coefficient (Hair et al., 2010). Average Variance Extracted (AVE; Fornell \& Larcker, 1981) $\geq .50$ are satisfactory (Fornell \& Larcker, 1981). For the overall NICOMACHUS Cronbach's a (Cronbach, 
1951), Bollen's $\omega$ (Bollen, 1980), Bentler's $\omega$ (Bentler, 1972, 2009) and McDonald's $\omega_{\mathrm{t}}$ (McDonald, 1999) were .93, .95, .95 and .93 respectively. AVE (Fornell \& Larcker, 1981) was .55. Internal consistency reliability coefficients for factors 1 - 4 ranged from .75 to .92 for $\alpha$, Bollen's $\omega$ and Bentler's $\omega$, and from .74 to .91 for McDonald's $\omega_{\mathrm{t}}$. AVE ranged from .54 to .63 (Table 12).

\section{Convergent and Discriminant Validity with other parenting measures}

Parenting measures were arranged in two groups: Positive and Non-Positive Parenting Practices Scales (Table 13). Generally, the correlations of the 4 NICOMACHUS factors, 2 combined factors (POPPD and BND dimensions) and overall NICOMACHUS with the Positive Parenting Practices Scales were all significant $(p<.001)$, with one exception (PBDQ AI with PC, $p<.05)$. Specifically, overall NICOMACHUS had positive moderately high correlations ( $p$ $<.001)$ with all the scales in the Positive Parenting Practices scales at a magnitude from $\mathrm{r}_{\mathrm{S}}(619)=.21, p<.001$ (APQ-9 PP) to $r_{\mathrm{S}}(619)=.53, p<.001(\mathrm{PBI} / \mathrm{E}$ $\mathrm{P})$, see Table 13. The two NICOMACHUS combined factors (POPD and BND) showed moderate to high correlations (all $p<.001$ ), ranging for POPD from $\mathrm{r}_{\mathrm{S}}$ $(619)=.24, p<.001$ (with KPSS) to $\mathrm{r}_{\mathrm{S}}(619)=.54, p<.001$ (with PBDQ EW) and for BND from $r_{\mathrm{S}}(619)=.15, p<.001$ (with APQ PP) to $\mathrm{r}_{\mathrm{S}}(619)=.43, p$ $<.001$ (with PBI S/E P). The correlations of the four NICOMACHUS factors ranged from $r_{\mathrm{S}}(619)=.12, p<.001$ (I with APQ-9 PP) to $\mathrm{r}_{\mathrm{S}}(619)=.49, p<.001$ (NV with PBI S/E P).

Conversely, the correlations of the four NICOMACHUS factors, two combined factors (POPPD and BND dimensions) and overall NICOMACHUS with the Non-Positive Parenting Practices Scales were significant (mainly $p<.001$ ) with few ns exceptions. Overall NICOMACHUS had significant negative correlations with all Negative Parenting Practices scales, $p<.001$ and $p<.05$ (with APQ-9 ID and PBDQ PED), from $r_{S}(619)=-.09, p<.05$ (APQ-9 ID) to $r_{\mathrm{S}}(619)$ $=-.29, p<.001$ (APQ-9 PS and PBI H/C P), Table 13. The two NICOMACHUS

Table 12. Internal consistency reliability $(\alpha)$, and model-based reliability and validity ( $\omega$ and AVE) for the overall NICOMACHUS and NICOMACHUS factors.

\begin{tabular}{cccccc}
\hline \multirow{2}{*}{$N=621$} & \begin{tabular}{c} 
Cronbach's \\
Alpha \\
\cline { 2 - 6 }
\end{tabular} & $\begin{array}{c}\text { Bollen's } \\
\text { Omega } \\
(\omega)\end{array}$ & $\begin{array}{c}\text { Bentler's } \\
\text { Omega } \\
(\omega)\end{array}$ & $\begin{array}{c}\text { McDonald's } \\
\text { Omega } \\
\left(\omega_{\mathrm{t}}\right)\end{array}$ & $\begin{array}{c}\text { Average } \\
\text { Variance } \\
\text { Extracted } \\
(\mathrm{AVE})\end{array}$ \\
\hline NICOMACHUS $(k=20)$ & .93 & .95 & .95 & .93 & .55 \\
Factor 1-NV $(k=9)$ & .92 & .92 & .92 & .91 & .55 \\
Factor 2-SIB $(k=5)$ & .85 & .85 & .85 & .85 & .54 \\
Factor 3-PC $(k=3)$ & .80 & .83 & .83 & .84 & .63 \\
Factor 4-I $(k=3)$ & .75 & .75 & .75 & .74 & .50 \\
\hline
\end{tabular}

NICOMACHUS Factors: Factor 1 = Nurturing Values (items 1 - 9), Factor 2 = Strength Identification \& Boosting (items 10 - 14), Factor 3 = Parenting Context (items 15 - 17), Factor 4 = Involvement (items, 18 $20)$. 
Table 13. Bivariate correlations of NICOMACHUS/NPP (four factors and two combined factors) with other parenting measures (6 questionnaires with 17 subscales).

\begin{tabular}{|c|c|c|c|c|c|c|c|}
\hline \multirow{2}{*}{$\begin{array}{c}\mathrm{N}=621 \\
\text { Validation } \\
\text { Measures }\end{array}$} & \multicolumn{7}{|c|}{ Spearman rho } \\
\hline & $\begin{array}{c}\text { NPP } \\
\text { Factor 1 } \\
\text { NV }\end{array}$ & $\begin{array}{c}\text { NPP } \\
\text { Factor } 2 \\
\text { SIB }\end{array}$ & $\begin{array}{c}\text { NPP } \\
\text { Factor } 3 \\
\text { PC }\end{array}$ & $\begin{array}{c}\text { NPP } \\
\text { Factor } 4 \\
\text { I }\end{array}$ & $\begin{array}{c}\text { Combined } 1 \\
(\mathrm{NPP} F I+F 2) \\
\text { POPPD }\end{array}$ & $\begin{array}{c}\text { Combined } 2 \\
(\mathrm{NPP} F 3+\mathrm{F} 4) \\
\text { BND }\end{array}$ & $\begin{array}{c}\text { NPP } \\
\text { Overall }\end{array}$ \\
\hline \multicolumn{8}{|c|}{ Positive Parenting Practices Scales } \\
\hline APQ-9 PP & $.25^{\star *}$ & $.22^{* *}$ & $.14^{* *}$ & $.12^{\star *}$ & $.26^{* *}$ & $.15^{\star *}$ & $.21^{* *}$ \\
\hline KPSS & $.18^{\star *}$ & $.24^{\star *}$ & $.32^{\star *}$ & $.14^{\star *}$ & $.24^{\star *}$ & $.30^{* *}$ & $.34^{* *}$ \\
\hline PBDQ EW & $.48^{* *}$ & $.46^{* *}$ & $.25^{* *}$ & $.36^{* *}$ & $.54^{* \star}$ & $.35^{* *}$ & $.49^{* *}$ \\
\hline PBDQ AS & $.45^{\star *}$ & $.34^{\star *}$ & $.23^{\star *}$ & $.17^{\star *}$ & $.43^{\star *}$ & $.25^{\star *}$ & $.38^{* *}$ \\
\hline PBDQ DD & $.41^{* *}$ & $.37^{* *}$ & $.21^{* *}$ & $.21^{* *}$ & $.43^{* *}$ & $.26^{* *}$ & $.39^{* *}$ \\
\hline PBDQ AI & $.22^{\star *}$ & $.25^{\star *}$ & $.10^{*}$ & $.25^{* *}$ & $.28^{* *}$ & $.21^{* *}$ & $.27^{\star *}$ \\
\hline PBI S/E P. & $.49^{* *}$ & $.39^{* *}$ & $.27^{* *}$ & $.44^{* *}$ & $.49^{* *}$ & $.43^{* *}$ & $.53^{* *}$ \\
\hline PSS PPT & $.33^{* *}$ & $.33^{* *}$ & $.33^{* *}$ & $.28^{* *}$ & $.37^{* *}$ & $.38^{* *}$ & $.44^{* *}$ \\
\hline \multicolumn{8}{|c|}{ Non-Positive Parenting Practices Scales } \\
\hline APQ-9 ID & $-.10^{\star}$ & $-.10^{* *}$ & -.05 & -.04 & $-.11^{\star *}$ & -.04 & $-.09^{*}$ \\
\hline APQ-9 PS & $-.24^{* *}$ & $-.22^{\star *}$ & $-.20^{* *}$ & $-.25^{\star *}$ & $-.25^{\star *}$ & $-.25^{\star *}$ & $-.29 * *$ \\
\hline PBDQ PD & $-.19^{* *}$ & $-.15^{* *}$ & $-.23^{* *}$ & $-.11^{\star *}$ & $-.18^{* *}$ & $-.20^{\star *}$ & $-.23^{* *}$ \\
\hline PBDQ PED & $-.15^{\star *}$ & $-.08^{*}$ & $-.13^{* *}$ & .04 & $-.12^{\star *}$ & -.06 & $-.10^{*}$ \\
\hline PCQ CD & $-.14^{* *}$ & $-.09^{*}$ & $-.20^{* *}$ & $-.09^{*}$ & $-.12^{\star *}$ & $-.18^{\star *}$ & $-.18^{* *}$ \\
\hline PCQ PC & $-.15^{\star *}$ & $-.13^{* *}$ & $-.17^{* *}$ & $-.15^{\star *}$ & $-.15^{\star *}$ & $-.19^{* *}$ & $-.21^{* *}$ \\
\hline PCQ F/E & -.07 & -.06 & $-.42^{* *}$ & $-.13^{\star *}$ & $-.08^{*}$ & $-.35^{\star *}$ & $-.29 * *$ \\
\hline PBI H/C P & -.04 & -.06 & $-.15^{* *}$ & 0.00 & -.05 & $-.10^{*}$ & $-.10^{*}$ \\
\hline PSS SPT & $-.20^{\star *}$ & $-.17^{\star \star}$ & $-.27^{\star \star}$ & $-.10^{*}$ & $-.20^{\star *}$ & $-.23^{\star *}$ & $-.25^{\star *}$ \\
\hline
\end{tabular}

Note. ${ }^{*}$ Significant at $p<.001$ level. ${ }^{*}$ Significant at $p<.05$ level. NICOMACHUS Factors. NV $=$ Nurturing Values, $\mathrm{SIB}=$ Strength Identification $\&$ Boosting, $\mathrm{PC}=$ Parenting Context, $\mathrm{I}=$ Involvement COMBINED 1 $($ Factors $1+2)=$ Parenting of Positive Psychology Dimension, COMBINED 2 (Factors $3+4)=$ Basic Needs Dimension. APQ-9 PP = APQ-9 Positive parenting, KPSS = Kansas Parental Satisfaction Scale, PBDQ EW $=$ PBDQ Emotional Warmth, PBDQ AS = PBDQ Autonomy Support, PBDQ DD = PBDQ Democratic Discipline, PBI S/E P. = PBI Supportive/Engaged Parenting, PSS PPT = PSS Positive Parenting Themes, APQ-9 $\mathrm{ID}=\mathrm{APQ}-9$ Inconsistent Discipline, APQ-9 PS = APQ-9 Poor Supervision, $\mathrm{PBDQ}$ AI $=$ PBDQ Anxious Intrusiveness, $\mathrm{PBDQ} P D=\mathrm{PBDQ}$ Punitive Discipline, $\mathrm{PBDQ} P E D=\mathrm{PBDQ}$ Permissive Discipline, $\mathrm{PCQ} C \mathrm{CD}$ $=$ PCQ Child Development problems, PCQ PC $=$ PCQ Parenting Capacity problems, PCQ F/E = PCQ Family/Environmental problems, PBI H/C P. = PBI Hostile/Coercive Parenting, PSS SPT $=$ PSS Stressful Parenting Themes.

combined factors had mostly significant negative correlations with the Non-Positive Parenting Practices Scales (almost all $p<.001$ and an $n s$ exception). The correlations ranged for POPD from $\mathrm{r}_{\mathrm{S}}(619)=-.05$, ns (with PBI H/C $\mathrm{P}$ ) to $\mathrm{r}_{\mathrm{S}}(619)=-.25, p<.001$ (with APQ-9 PS) and for BND from $\mathrm{r}_{\mathrm{S}}(619)=$ -.04 , ns (with APQ-9 ID) to $\mathrm{r}_{\mathrm{S}}(619)=-.35, p<.001$ (with PCQ F/E). Most correlations of NICOMACHUS factors with the Non-Positive Parenting Practices Scales were significant $(p<.001)$, with three exceptions at $p<.05$ and few $n s$. 
Specifically, there was no correlation between NICOMACHUS factor I and PBI $\mathrm{H} / \mathrm{C} \mathrm{P}$. The magnitude of the remaining correlations ranged from $\mathrm{r}_{\mathrm{S}}(619)=$ $-.04, n s$ (I with APQ-ID and NV with PBI H/C P) to $\mathrm{r}_{\mathrm{S}}(619)=-.42, p<.001$ (PC with PCQ F/E). All correlations are presented in Table 13.

\section{Descriptive Statistics and Standardization of NICOMACHUS Scores}

NICOMACHUS factor scores for the NV, SIB, PC and I factors were $M=$ 4.39, $M=4.19, M=4.12$ and $M=4.10$ respectively. The overall NICOMACHUS had $M=4.20$. The $10^{\text {th }}, 25^{\text {th }}, 50^{\text {th }}, 75^{\text {th }}$, and $90^{\text {th }}$ percentile was calculated $(N=$ $621)$. For NV, SIB, PC and I, $50 \%$ of the respondents had $M \leq 4.56, \leq 4.40, \leq 4.33$ and $\leq 4.33$ respectively. For the overall NICOMACHUS, 50\% of the parents had $M \leq 4.31$ (Table 14). For each NICOMACHUS measured variable the highest mean was observed on item $3(M=4.66, S D=0.83)$ equivalent to Mostly True Absolutely True Likert points. The lowest mean was observed on item 18 ( $M=$ 3.91, $S D=1.15$ (Can't Say True or Untrue-Mostly True). Table 14 presents the percentile means and Table 8 the measured variables mean. Finally, all the NICOMACHUS scale-level correlations were significant, $p<.001$. The correlations between overall NICOMACHUS and NV, SIB, PC and I factors were $r_{\mathrm{S}}$ $(619)=.70, .69, .74$ and .72 respectively $(p<.001)$. All the scale-level correlations are listed in Table 15.

Table 14. Percentiles of the NICOMACHUS overall and the NICOMACHUS factor scores.

\begin{tabular}{cccccccc}
\hline & \multicolumn{5}{c}{ Percentile } \\
Total Sample $(N=621)$ & Mean & Range & 10 & 25 & 50 & 75 & 90 \\
\hline Factor 1-NV & 4.39 & $1.11-5.00$ & 3.78 & 4.22 & $\mathbf{4 . 5 6}$ & 4.89 & 5.00 \\
Factor 2-SIB & 4.19 & $1-5$ & 3.40 & 3.80 & 4.40 & 4.8 & 5.00 \\
Factor 3-PC & 4.12 & $1-5$ & 2.67 & 3.67 & 4.33 & 5.00 & 5.00 \\
Factor 4- I & 4.10 & $1-5$ & 2.67 & 3.67 & 4.33 & 4.67 & 5.00 \\
NICOMACHUS & 4.20 & $1.03-5.00$ & 3.51 & 3.98 & 4.31 & 4.62 & 4.83 \\
\hline
\end{tabular}

NICOMACHUS Factors: Factor 1 = Nurturing Values (items 1 - 9), Factor $2=$ Strength Identification \& Boosting (items 10 - 14), Factor 3 = Parenting Context (items 15 - 17), Factor 4 = Involvement (items, 18 20).

Table 15. Scale level correlations of the overall NICOMACHUS/NPP, the four NPP factors (NV, SIB, PC, I) and two combined factors (POPPD \& BND).

\begin{tabular}{|c|c|c|c|c|c|c|c|}
\hline Total Sample $(N=621)$ & NV & SIB & PC & I & POPPD & BND & NPP \\
\hline Factor 1-Nurturing Values (NV) & - & & & & & & \\
\hline Factor 2-Strength Identification \& Boosting (SIB) & $.58^{\star *}$ & - & & & & & \\
\hline Factor 3-Parenting Context (PC) & $.34^{* *}$ & $.32^{\star *}$ & - & & & & \\
\hline Factor 4-Involvement (I) & $.46^{* *}$ & $.38^{* *}$ & $.31^{* *}$ & - & & & \\
\hline Combined 1 -Parenting of PP Dimension (POPPD) & $.84^{* *}$ & $.92^{\star *}$ & $.36^{* *}$ & $.45^{\star *}$ & - & & \\
\hline Combined 2-Basic Needs Dimension (BND) & $.46^{* *}$ & $.40^{* *}$ & $.83^{* *}$ & $.76^{\star *}$ & $.46^{\star *}$ & - & \\
\hline Overall NICOMACHUS/NPP & $.70^{* *}$ & $.69^{* *}$ & $.74^{* *}$ & $.72^{\star *}$ & $.77^{\star *}$ & $.91^{* *}$ & - \\
\hline
\end{tabular}

Note. ${ }^{*}$ Significant at $p<.001$ level. POPPD $=$ NPP Factors $1+2$ (Parenting of Positive Psychology Dimension), BND $=$ NPP Factors $3+4$ (Basic Needs Dimension). 


\section{Study 2 Discussion}

The purpose of this study was: 1) to establish construct validity with EFA and CFA in a large sample; 2) to evaluate measurement invariance across child gender; 3) to evaluate internal consistency reliability and factor-based reliability; 4) to examine model-based convergent validity; 5) to establish the convergent and discriminant validity with other parenting measures and 6) to calculate normative data for the newly developed NICOMACHUS.

The sample $(N=621)$ was split into two random subsamples, to carry out EFA and CFA in different parts of the sample (30\% and $70 \%$ or about $1 / 3$ and 2/3; Guadagnoli \& Velicer, 1988; Singh et al., 2016). EFA was carried out in a random 30\% of the sample. Using multiple methods (Cattell, 1978; Horn, 1965; Velicer, 1976; Schwartz, 1978) four factors were extracted explaining over two-thirds of the total variance, with no cross-loadings. Loadings, communalities, and factor correlations were above the acceptable limits and the model fit was adequate.

The four factors that emerged were in accordance with the theoretical model proposed (Introduction \& Kyriazos \& Stalikas, 2018a). Factor 1 was termed Nurturing Values (NV), Factor 2 Strength Identification and Boosting (SIB), Factor 3 Parenting Context (PC), and Factor 4 was named Involvement (I). By merging Factor 1 and 2 we get the Parenting of Positive Psychology Dimension (POPPD), and by merging Factors 3 with 4 we get the Basic Needs Dimension (BND).

This four-factor structure was verified with a CFA in a random $70 \%$ of the sample. Two variations of the 4 -factor model were specified. One with four correlated factors and a second with four correlated factors plus two error covariances. Item 2 ( $I$ encourage my child to fight for what is fair) was allowed to covary with item 3 ( $I$ incite my child to always tell the truth) and item 13 (I encourage my child to study something related to his/her character strengths) with item 14 (I make sure that my child's extracurricular activities cultivate his/her character strengths). Both models showed adequate to good fit respectively. However, the model with error covariances is less parsimonious than the 4-factor model, and it must be cross-validated in a different sample (Byrne, 2012 among others).

Measurement invariance was estimated using the 4 -factor model (without error covariances) as a baseline model across the child gender and it was fully supported to the strict level, i.e. the strictest possible measurement invariance level (Wang \& Wang, 2012).

Internal consistency reliability was estimated with four coefficients: Cronbach's alpha (1951) and at the model, level using three omega methods (Bollen, 1980; Bentler, 1972, 2009; McDonald, 1999; Werts, Lim, \& Joreskog, 1974). All findings varied from well above acceptable to excellent levels both for the overall NICOMACHUS and per factor. Crucially, they all showed comparable magnitude, cross-validating one-another. Moreover, convergent validity at the model level (Fornell \& Larcker, 1981) also varied from satisfactory to very good (For- 
nell \& Larcker, 1981).

Convergent and discriminant validity were also examined with six parenting measures, with positive and non-positive parenting practices subscales. All the positive subscales had the expected direction (positive), a high statistical significance and low to moderate magnitude, both for the overall NICOMACHUS, factors and combined factors (POPPD and BND dimensions). The negative subscales had also the expected direction (negative) and they were mostly highly significant with a few non-significant exceptions. Descriptive statistics and normative data were also evaluated.

The next step was to cross-validate the newly developed NICOMACHUS in a different sample (Study 3).

\section{Study 3: Cross-Validation Study}

The purpose of this study was: 1) to cross-validate the NICOMACHUS structure found in Study 2 in an independent sample, 2) to reevaluate internal consistency reliability and factor-based reliability and convergent validity, 3) to examine convergent and discriminant validity with wellbeing and affect measures, 4) to examine concurrent validity with the child's school performance, 5) to re-calculate normative data for NICOMACHUS in a different sample.

\section{Study 3 Method}

\section{Participants}

The sample involved 146 Greek parents (75\% of females) with at least one child from 7 to 13 years ( $M=9.84$ years, $S D=2.18,57 \%$ of males). The parents were $75 \%$ of biological mothers and $25 \%$ biological fathers. Per family there were either $1(27 \%), 2(61 \%), 3(12 \%)$ or more $(1 \%)$ children. The majority of the parents (99\%) were living in the same house with the child they completed the questionnaire for, and $97 \%$ of them cared for a child with no special needs (biological, mental or other). Almost half of them (47\%) were from 41 - 50 years, $45 \%$ from 31 - 40 years, $7 \%$ from 51 - 60. Almost half the participants (48\%) had a B.A. (27\%) or higher (21\%), or they had finished high-school (40\%) or lower (2\%). The majority of the parents were working (86\%), and had a Greek nationality (98\%). Most parents (45\%) had an annual income between 10001 and $20000 €$ or lower $(21 \%)$ while $23 \%$ had an income between 20001 and $30000 €$ or higher (11\%).

\section{Measures}

\section{NICOMACHUS-Positive Parenting (NPP)}

NICOMACHUS emerged from Study 2 and it is measuring Positive Parenting for children aged from 7 - 13 years. It contains 20 items rated on a 5-point Likert scale ( 1 = Absolutely Untrue, 2 = Mostly Untrue, 3 = Can't Say True or Untrue, $4=$ Mostly True, 5 = Absolutely True) tapping 4 factors. Factor 1 is Nurturing Values (NV), Factor 2 is Strength Identification and Boosting (SIB), Factor 3 is Parenting Context (PC), Factor 4 is Involvement (I). From this structure, two compound dimensions are hypothesized. By merging Factor 1 with 2 we have the Parenting of Positive Psychology Dimension (POPPD) and by merging Fac- 
tors 3 with 4 we have the Basic Needs Dimension (BND). The higher the score the higher the perceived positive parenting. There are no reverse-scored items. Possible scores range from 1 (minimum positive parenting effectiveness) to 5 (maximum positive parenting effectiveness). The questionnaire is available in Appendix.

PERMA Profiler (Butler \& Kern, 2016)

PERMA-Profiler is a 23-item measure of the PERMA wellbeing model (Seligman, 2011) with five theoretical domains (Positive emotion, Engagement, Relationships, Meaning, and Accomplishment). PERMA-Profiler contains 3 items on each PERMA theoretical domain and 8 filler items to evaluate overall wellbeing, negative emotion and physical health. The 23 items are rated on a 11-point $\mathrm{Li}$ kert scale from $0=$ never/terrible/not at all/to $10=$ always/excellent/completely depending the item. Combined reliability coefficients $(\alpha)$ across 11 samples were reported $.88(\mathrm{P}), .72(\mathrm{E}), .82(\mathrm{R}), .90(\mathrm{M}), .79(\mathrm{~A}), .94(\mathrm{OWB}), .71(\mathrm{NE})$, and .92 $(\mathrm{PH})$, i.e. Positive Emotion, Engagement, Relationships, Meaning, Accomplishment, Overall Wellbeing, Negative Emotion, and Physical Health respectively (Butler \& Kern, 2016). In the present study, internal consistency reliability was a $=.91$.

Mental Health Continuum-Short Form (MHC-SF; Keyes et al., 2008)

MHC-SF (Keyes et al., 2008) is 14-item questionnaire measuring three aspects of wellbeing over three factors (Keyes, 2002): emotional (EWB), social (SWB) and psychological wellbeing (PWB). Items are rated on a 6-point scale evaluating the frequency of experiences during the past month (from $0=$ never to $5=$ every day). Moreover, MHC-SF generates a categorical assessment (flourishing, moderately mentally healthy, and languishing). Internal consistency reliability was reported by Lamers et al. (2011) to be $\alpha=.89, .83, .83$ and .74 for the total MHC-SF, EWB, PWB, and SWB respectively. In the present study, internal consistency reliability was $\alpha=.89$.

Satisfaction with Life Scale (SWLS; Diener, Emmons, Larsen, \& Griffin, 1985)

SWLS is a commonly used measure of life satisfaction with five items about cognitive appraisals of one's life (e.g. "I am satisfied with my life"). Responses are rated on a 7 -point Likert scale (from $1=$ strongly disagree to $7=$ strongly agree). The higher the score the greater the perceived life satisfaction. Possible scores range from 1 (min life satisfaction) to 35) max life satisfaction). Internal consistency was reported to range from .79 to .89; Pavot \& Diener, 1993). In the present study, internal consistency reliability was $\alpha=.88$.

Subjective Happiness Scale (SHS; Lyubomirsky \& Lepper, 1999)

The SHS is a short measure of the perceived happiness with 4 items rated on a 7 -point Likert scale (from $1=$ not a very happy person to $7=$ very happy person). Higher scores suggest higher mean happiness. Lyubomirsky and Lepper (1999) reported internal consistency reliability from .79 to .94 across several studies. In the present study, internal consistency reliability was $\alpha=.77$. 
Scale of Positive and Negative Experience 8 (SPANE-8; Diener et al., 2009; Kyriazos et al., 2018b)

This is a shorter version of SPANE (Diener et al., 2009; Kyriazos et al, 2018b) with 8 items. SPANE-8 contains one general feeling per dimension instead of 3 in the original (Diener et al., 2009: p. 145). Among the items of general positive/negative feelings, those with the lowest CFA factor loadings were discarded (Kyriazos et al., 2018b). This resulted in a briefer measure with 4 positive items (Pleasant, Happy, Joyful, Contented) and 4 negatives (Bad, Sad, Afraid, Angry). In the present study, internal consistency reliability was $\alpha=.89$ (SPANE-8 P) and .77 (SPANE-8 N).

\section{School Performance}

Parents were asked to evaluate the school performance of the child, they completed the questionnaire for in the following four knowledge fields: 1) Language, 2) Mathematics, 3) History and 4) Arts. A 5-point performance scale was used from $1=$ Very poor to $5=$ Very good.

\section{Procedure}

The procedure was similar to Study 1 and 2. In this study, 15 students of a psychometrics class recruited on average 10 parents $(M=9.7)$ having at least one child aged 7 - 13 years.

\section{Research Design}

An overview of Study 3 analyses is presented in Table 16. The tools of data collection and analysis were identical with those of Study 2.

\section{Study 3 Results}

The data contained no missing values. Out of 146 cases 3 multivariate outliers were identified, with scores $>$ Mahalanobis' distance critical value, $\chi^{2}[20]=$ $45.32, p<.001$ (Mahalanobis, 1936). However, the outliers were kept in the dataset because there was only a minimal deterioration in findings with them included. The final sample was $N=146$ cases. The hypothesized model had 20

Table 16. Research analyses overview in study 3.

\begin{tabular}{|c|c|}
\hline Sequence & Analyses Carried out \\
\hline 1 & $\begin{array}{ll}\text { - } & \text { Univariate Normality } \\
\text { - } & \text { Multivariate Normality with multiple tests } \\
\text { - } & \text { Power Analysis based on Population RMSEA } \\
& \text { (MacCallum, Browne, \& Sugawara, 1996) }\end{array}$ \\
\hline 2 & Confirmatory Factor Analysis for cross-validating the Models emerged in Study 2 \\
\hline 3 & $\begin{array}{l}\text { - Internal Consistency Reliability using a coefficient (Cronbach, 1951) } \\
\text { _ } \quad \text { Model-Based Reliability (Mair, 2018; Sha \& Ackerman, 2018) using three } \omega \\
\text { coefficients (Bollen, 1980; Bentler, 1972, 2009; McDonald, 1999) } \\
\text { - Model Based Convergent Validity using Average Variance Extracted } \\
\quad \text { (AVE; Fornell \& Larcker, 1981) }\end{array}$ \\
\hline 4 & $\begin{array}{l}\text { - Convergent/Discriminant Validity with wellbeing measures } \\
\text { - Convergent/Discriminant Validity with affect measures } \\
\text { - Concurrent validity child's school performance }\end{array}$ \\
\hline 5 & $\begin{array}{ll}\text { - } & \text { Descriptive Statistics } \\
\text { - } & \text { Normative Data in overall NICOMACHUS/NPP and per factor }\end{array}$ \\
\hline
\end{tabular}


measured variables and 4 correlated factors. The ratio of cases to observed variables was 7:1. The ratio of cases to estimated parameters was 4:1. Power analysis for the most complex model specified (4 correlated factors with 2 error covariances) using the population RMSEA method (MacCallum, Browne, \& Sugawara, 1996; Hancock \& Freeman, 2001) suggested a $N \geq 96$ cases (RMSEA0 $=.05$, RMSEA $\alpha=.08, \mathrm{df}_{\mathrm{M}}=162$, power $\left.=.80, N=146\right)$.

\section{Univariate and Multivariate Normality}

The univariate and multivariate normality assumption was evaluated using the same tests as in Study 2. The univariate tests were statistically significant ( $p$ $<.001)$ for all 20 NICOMACHUS measured variables and the same was true for the multivariate tests (Table 17).

Table 17. Descriptive Statistics, univariate normality tests and Multivariate Normality Tests for each NICOMACHUS/NPP measured variable.

\begin{tabular}{|c|c|c|c|c|c|c|c|c|c|c|}
\hline \multirow{2}{*}{$\begin{array}{l}\text { Measured } \\
\text { Variables }\end{array}$} & \multicolumn{4}{|c|}{ Descriptive Statistics $(N=146)$} & \multicolumn{6}{|c|}{ Univariate Normality Tests $(N=146)$} \\
\hline & Mean $(M)$ & St.Dev. $(S D)$ & Skew & Kurtosis & Kolmogc & orov-Smirnov & Shapiro-Wilk & Shapiro-Francia & Ander & son-Darling \\
\hline ITEM 1 & 4.06 & 1.06 & -.95 & .06 & & .26 & .81 & .81 & & 10.67 \\
\hline ITEM 2 & 4.58 & .95 & -2.65 & 6.56 & & .44 & .50 & .50 & & 30.62 \\
\hline ITEM 3 & 4.60 & .92 & -2.49 & 5.61 & & .46 & .50 & .50 & & 32.19 \\
\hline ITEM 4 & 4.35 & .95 & -1.74 & 2.89 & & .32 & .69 & .69 & & 16.67 \\
\hline ITEM 5 & 4.29 & .89 & -1.19 & 1.16 & & .31 & .76 & .76 & & 14.05 \\
\hline ITEM 6 & 4.17 & 1.08 & -1.16 & .46 & & .31 & .76 & .76 & & 14.05 \\
\hline ITEM 7 & 4.05 & 1.04 & -.96 & .33 & & .25 & .81 & .82 & & 10.00 \\
\hline ITEM 8 & 4.29 & .94 & -1.39 & 1.69 & & .31 & .74 & .75 & & 14.22 \\
\hline ITEM 9 & 4.29 & .94 & -1.39 & 1.48 & & .30 & .74 & .74 & & 14.43 \\
\hline ITEM 10 & 4.21 & .96 & -1.51 & 2.44 & & .25 & .75 & .75 & & 12.60 \\
\hline ITEM 11 & 4.34 & .97 & -1.8 & 3.1 & & .32 & .69 & .69 & & 16.83 \\
\hline ITEM 12 & 4.12 & .83 & -1.02 & 1.21 & & .28 & .80 & .80 & & 11.68 \\
\hline ITEM 13 & 3.96 & 1.06 & -.83 & 0 & & .22 & .84 & .84 & & 8.64 \\
\hline ITEM 14 & 4.03 & .98 & -.81 & .04 & & .22 & .84 & .84 & & 9.10 \\
\hline ITEM 15 & 3.79 & 1.41 & -.84 & -.7 & & .26 & .79 & .80 & & 11.84 \\
\hline ITEM 16 & 4.11 & 1.13 & -1.17 & .37 & & .28 & .76 & .77 & & 13.53 \\
\hline ITEM 17 & 3.95 & 1.34 & -1.03 & -.26 & & .28 & .76 & .77 & & 13.83 \\
\hline ITEM 18 & 3.80 & 1.1 & -.78 & .02 & & .23 & .86 & .86 & & 7.27 \\
\hline ITEM 19 & 4.45 & .88 & -1.71 & 2.69 & & .37 & .67 & .67 & & 19.74 \\
\hline ITEM 20 & 4.28 & .9 & -1.31 & 1.52 & & .29 & .76 & .76 & & 13.37 \\
\hline \multicolumn{11}{|c|}{ Multivariate Normality Tests } \\
\hline & & \multicolumn{2}{|c|}{ Mardia's Skew } & \multicolumn{2}{|c|}{ Mardia's kurtosis } & Henze-Zirk & \multicolumn{2}{|c|}{ Doornik-Hansen $(d f)$} & -statistic & Royston \\
\hline \multicolumn{2}{|c|}{ Total sample $(N=146)$} & \multicolumn{2}{|c|}{2841.06} & \multicolumn{2}{|c|}{14.02} & 1.08 & \multicolumn{2}{|c|}{459.37} & 3.56 & 1181.82 \\
\hline
\end{tabular}

Note. All univariate and multivariate normality tests were significant at $p<.001$ level. 


\section{Confirmatory Factor Analysis}

For the parameter estimator and goodness of fit criteria see Study 2. The four Models of Study 2 were retested in this new sample $(N=146)$ to cross-validate model fit.

Regarding model fit, the maximum parsimony hypothesis was rejected (MODEL A). The two-factor ICM-CFA model (MODEL B) also showed poor performance. The 3-factor model (MODEL C) confirmed the adequate fit, with all fit indicators and factor loadings within acceptability. Crucially, the optimal model of Study 2 (MODEL D) was also reconfirmed in this cross-validation CFA. MODEL D was a variation of MODEL $\mathrm{C}$ with two error covariances added (item 2 with item 3 and item 13 with item 14). Taking into consideration: 1) the fit statistics, factor loadings, and factor correlations and 2) the cross-validation of error covariances added MODEL D showed the optimal fit. The fit statistics and the standardized loadings of all models are presented in Table 18.

Internal Consistency Reliability, Model-Based Reliability and Validity

For the overall NICOMACHUS Cronbach's a (Cronbach, 1951), Bollen's $\omega$ (Bollen, 1980), Bentler's $\omega$ (Bentler, 1972, 2009) and McDonald's $\omega_{\mathrm{t}}$ (McDonald, 1999) were .92, .93, .93 and .91 respectively. AVE (Fornell \& Larcker, 1981) was .52. Internal consistency reliability coefficients for each factor ranged from .62 to .89 ( $\alpha$ ), .60 to .89 (Bollen's $\omega$ ), 60 to .89 (Bentler's $\omega$ ), 59 to .89 (McDonald's $\omega_{\mathrm{t}}$ ). AVE ranged from .34 - .73 (Table 19).

Convergent and Discriminant Validity with wellbeing, affect measures \& Concurrent validity child's school performance

Convergent and Discriminant Validity with wellbeing and affect measures

Table 18. Goodness of fit measures, factor loadings and factor Inter-correlations for the NICOMACHUS/NPP CFA models.

\begin{tabular}{|c|c|c|c|c|c|c|c|c|c|c|c|c|c|}
\hline \multirow{2}{*}{ Model } & \multirow[b]{2}{*}{$x^{2}$} & \multirow[b]{2}{*}{$D f$} & \multicolumn{9}{|c|}{$\begin{array}{l}\text { RMSEA } \\
90 \% \text { CI }\end{array}$} & \multirow[t]{2}{*}{$\begin{array}{l}\text { Factor } \\
\text { Loadings }\end{array}$} & \multirow{2}{*}{$\begin{array}{l}\quad \begin{array}{c}\text { Factor } \\
\text { Intercorrelations }\end{array} \\
\text { Range }\end{array}$} \\
\hline & & & $x^{2} / d f$ & CFI & TLI & RMSEA & Low & High & SRMR & BIC & AIC & & \\
\hline $\begin{array}{l}\text { MODEL } \\
\text { A Single } \\
\text { factor }\end{array}$ & 514.28 & 170 & 3.03 & .750 & .721 & .118 & .107 & .129 & .086 & 735.73 & 7231.39 & $.234-.819$ & - \\
\hline $\begin{array}{c}\text { MODEL B } \\
\text { 2-factor } \\
(\mathrm{F} 1, \mathrm{~F} 2)-(\mathrm{F} 3, \mathrm{~F} 4)\end{array}$ & 446.19 & 169 & 2.64 & .799 & .774 & .106 & .095 & .118 & .134 & 727.1 & 7148.66 & $.186-.900$ & .526 \\
\hline $\begin{array}{l}\text { MODEL C } \\
\text { 4-factor }\end{array}$ & 318.9 & 164 & 1.94 & .888 & .870 & .080 & .068 & .093 & .079 & 7159.13 & 7021.89 & $.373-.886$ & $.328-.873$ \\
\hline $\begin{array}{l}\text { MODEL D } \\
\text { 4-factor with } \\
\text { error cov. }\end{array}$ & 264.97 & 162 & 1.64 & .925 & .912 & .066 & .052 & .080 & .075 & 7107.17 & 6963.95 & $.377-.885$ & $.327-.877$ \\
\hline
\end{tabular}

Note. Estimator = MLR; Bold typeface indicates optimal fit. $\mathrm{df}=$ Degrees of freedom; CFI = Comparative Fit Index; TLI = Tucker-Lewis index; RMSEA = Root Mean Square Error of Approximation; CI = Confidence Interval; SRMR = Standardized Root Mean Square Residual, AIC = Akaike Information Criterion, BIC = Bayesian Information Criterion, Factor $1=$ Nurturing Values (NV, items 1 - 9), Factor 2 = Strength Identification \& Boosting (SIB, items 10 14), Factor 3 = Parenting Context (PC, items 15 - 17), Factor 4 = Involvement (I, items, 18 - 20). 
Table 19. Internal consistency reliability ( $\alpha$ ), and model-based reliability and validity ( $\omega$ and AVE) for NICOMACHUS/NPP.

\begin{tabular}{cccccc}
\hline & \multicolumn{5}{c}{ Coefficient } \\
\cline { 2 - 6 }$(N=146)$ & $\begin{array}{c}\text { Cronbach's } \\
\text { Alpha } \\
(\alpha)\end{array}$ & $\begin{array}{c}\text { Bollen's } \\
\text { Omega } \\
(\omega)\end{array}$ & $\begin{array}{c}\text { Bentler's } \\
\text { Omega } \\
(\omega)\end{array}$ & $\begin{array}{c}\text { McDonald's } \\
\text { Omega } \\
\left(\omega_{\mathrm{t}}\right)\end{array}$ & $\begin{array}{c}\text { Average } \\
\text { Variance } \\
\text { Extracted } \\
(\text { AVE })\end{array}$ \\
\hline NICOMACHUS $(k=20)$ & .92 & .93 & .93 & .91 & .52 \\
Factor 1-NV $(k=9)$ & .89 & .89 & .89 & .89 & .48 \\
Factor 2-SIB $(k=5)$ & .81 & .76 & .76 & .76 & .46 \\
Factor 3-PC $(k=3)$ & .85 & .88 & .88 & .89 & .73 \\
Factor 4-I $(k=3)$ & .62 & .60 & .60 & .59 & .34 \\
\hline
\end{tabular}

NICOMACHUS Factors: Factor 1 = Nurturing Values (items 1 - 9), Factor $2=$ Strength Identification \& Boosting (items 10 - 14), Factor 3 = Parenting Context (items 15 - 17), Factor $4=$ Involvement (items, 18 20).

All the correlations of overall NICOMACHUS with the wellbeing scales (Table 20) were highly significant $(p<.001)$, ranging in magnitude from $r_{\mathrm{S}}(144)$ $=.22, p<.001$ (PERMA E) to $r_{\mathrm{S}}(144)=.42, p<.01\left(\right.$ PERMA P) or $r_{\mathrm{S}}(144)=.41$, $p<.001$ (SWLS). The overall NICOMACHUS correlations with the affect scales ranged from $r_{\mathrm{S}}(144)=-.26, p<.001\left(\right.$ SPANE-8 N) to $r_{\mathrm{S}}(144)=.40, p<.001$ (SPANE-8 P).

About the correlations of the four NICOMACHUS factors with wellbeing, NV was weakly but significantly correlated with wellbeing scales $(p<.001$ and $p$ $<.05)$ with the exception of PERMA $\mathrm{R}(n s)$. The correlation magnitudes ranged from $r_{\mathrm{S}}(144)=.16, n s$ (PERMA R) to $r_{\mathrm{S}}(144)=.30, p<.001$ (MHC-SF PWB). SIB was also weakly but significantly correlated with almost all wellbeing scales $(p<.001$ and $p<.05)$, with the exception of SWLS, PERMA R and PERMA H. Magnitudes ranged from $r_{\mathrm{S}}(144)=.10, n s$ (PERMA R) to $r_{\mathrm{S}}(144)=.24, p<.001$ (PERMA M). PC had moderately high and significant correlations (all but one at $p<.001$ ), from $r_{\mathrm{S}}(144)=.14$, ns (PERMA E) to $r_{\mathrm{S}}(144)=.45, p<.001$ (SWLS and PERMA P). I had non-significant low correlations with almost all wellbeing scales except PERMA H $(p<.05)$. The correlations of the NICOMACHUS factors with the affect scales were in the expected direction. Specifically, NV and SIB had a similar pattern of correlations both significant $(p<.05$ with SPANE- 8 P) and non-significant (with PERMA NE and SPANE-8 N). In contrast, PC and I had an inverse pattern of highly significant correlations $(p<.001)$ and non-significant correlations respectively. See all NICOMACHUS correlations in Table 20.

\section{Concurrent validity with child's school performance}

Generally, the correlations were non-significant, with the exception of SIB factor, POPPD combined factor and mathematics with the overall NICOMACHUS $(p<.05)$. Specifically, the overall NICOMACHUS had positive, mostly non-significant, low to moderate correlations with all learning fields, 
Table 20. Bivariate Correlations of the four NICOMACHUS/NPP factors (1-4_ and overall NPP with Wellbeing and Affect measures.

\begin{tabular}{|c|c|c|c|c|c|}
\hline \multirow{2}{*}{$\begin{array}{c}N=146 \\
\text { Validation } \\
\text { Measures }\end{array}$} & \multicolumn{5}{|c|}{ Spearman rho } \\
\hline & $\begin{array}{c}\text { NPP } \\
\text { Factor } 1 \\
\text { NV }\end{array}$ & $\begin{array}{c}\text { NPP } \\
\text { Factor } 2 \\
\text { SIB }\end{array}$ & $\begin{array}{c}\text { NPP } \\
\text { Factor } 3 \\
\text { PC }\end{array}$ & $\begin{array}{c}\text { NPP } \\
\text { Factor } 4 \\
\text { I }\end{array}$ & $\begin{array}{c}\text { NPP } \\
\text { Overall }\end{array}$ \\
\hline \multicolumn{6}{|c|}{ Wellbeing Scales } \\
\hline Satisfaction with Life Scale (SWLS) & $.18^{*}$ & .15 & $.45^{* *}$ & .07 & $.41^{* *}$ \\
\hline Subjective Happiness Scale (SHS) & $.22^{* *}$ & $.18^{*}$ & $.39^{* *}$ & -.01 & $.30^{* *}$ \\
\hline MHC-SF Emotional wellbeing (EWB) & $.17^{\star}$ & .16 & $.34^{* *}$ & .08 & $.32^{* *}$ \\
\hline MHC-SF social wellbeing (SWB) & $.27^{\star *}$ & $.16^{*}$ & $.19^{*}$ & .12 & $.30^{* *}$ \\
\hline MHC-SF psychological wellbeing (PWB) & $.30^{* *}$ & $.22^{* *}$ & $.26^{* *}$ & .14 & $.36^{* *}$ \\
\hline MHC-SF ALL & $.28^{* *}$ & $.20^{*}$ & $.30^{* *}$ & .13 & $.37^{\star *}$ \\
\hline PERMA Positive emotion (P) & $.27^{* *}$ & $.19^{*}$ & $.45^{* *}$ & .10 & $.42^{* *}$ \\
\hline PERMA Engagement (E) & $.25^{\star *}$ & $.23^{* *}$ & .14 & .01 & $.22^{* *}$ \\
\hline PERMA Relationships (R) & .16 & .10 & $.48^{* *}$ & .02 & $.39 * *$ \\
\hline PERMA Meaning (M) & $.23^{* *}$ & $.24^{* *}$ & $.28^{* *}$ & .05 & $.30^{* *}$ \\
\hline PERMA Accomplishment (A) & $.28^{* *}$ & $.21^{*}$ & $.34^{* *}$ & .06 & $.35^{* *}$ \\
\hline PERMA Physical health $(\mathrm{H})$ & $.20^{*}$ & .14 & $.27^{* *}$ & $.17^{*}$ & $.31^{* *}$ \\
\hline \multicolumn{6}{|c|}{ Affect scales } \\
\hline PERMA Negative Emotion (NE) & -.08 & -.05 & $-.25^{\star *}$ & .05 & -.16 \\
\hline SPANE-8 Positive Experiences (SPANE-8 P) & $.19^{*}$ & $.18^{*}$ & $.44^{* *}$ & .11 & $.40^{* *}$ \\
\hline SPANE-8 Negative Experiences (SPANE-8 N) & -.04 & -.09 & $-.35^{\star *}$ & .02 & $-.26^{* *}$ \\
\hline
\end{tabular}

Note. ${ }^{*}$ Significant at $p<.001$ level, ${ }^{*}$ Significant at $p<.05$ level. NICOMACHUS Factors: Factor $1=$ Nurturing Values (items $1-9$ ), Factor $2=$ Strength Identification \& Boosting (items $10-14$ ), Factor $3=\mathrm{Pa}$ renting Context (items 15 - 17), Factor $4=$ Involvement (items, 18 - 20).

except mathematics, $r_{\mathrm{S}}(144)=.24, p<.05$. The POPPD combined dimension had positive non-significant low to moderate correlations with all learning fields, except history $\left(r_{\mathrm{S}}(144)=.27, p<.05\right)$ and mathematics $\left(r_{\mathrm{S}}(144)=.25, p<.05\right)$. The BND combined factor had non-significant, low correlations with all learning fields both positive (mathematics and arts) and negative (language, history). The NV factor had positive, non-significant low correlations with all learning fields. In contrast, the SIB factor had positive, mostly significant $(p<.05)$ low to moderate correlations with all learning fields except arts, from $r_{\mathrm{S}}(144)=.14$, ns (arts) to $r_{\mathrm{S}}(144)=.29, p<.05$ (language). The NV factor had non-significant low positive correlations (with mathematics and arts), no correlation (with language) or negative correlation (with history). A similar pattern was found for the I factor. See all NICOMACHUS correlations in Table 21.

Descriptive Statistics and Standardization of NICOMACHUS Scores 
Table 21. Bivariate Correlations of NICOMACHUS /NPP (four factors and two combined factors) with Child's school performance in four learning fields.

\begin{tabular}{|c|c|c|c|c|c|c|c|}
\hline$N=146$ & & & & Spearman & rho & & \\
\hline Learning Fields & $\begin{array}{c}\text { NPP } \\
\text { Factor } 1 \\
\text { NV }\end{array}$ & $\begin{array}{c}\text { NPP } \\
\text { Factor } 2 \\
\text { SIB }\end{array}$ & $\begin{array}{c}\text { NPP } \\
\text { Factor } 3 \\
\text { PC }\end{array}$ & $\begin{array}{c}\text { NPP } \\
\text { Factor } 4 \\
\text { I }\end{array}$ & $\begin{array}{c}\text { NPP } \\
\text { Combined } 1 \\
\text { (FI + F2) } \\
\text { POPPD }\end{array}$ & $\begin{array}{c}\text { NPP } \\
\text { Combed } 2 \\
(\mathrm{~F} 3+\mathrm{F} 4) \\
\text { BND }\end{array}$ & $\begin{array}{c}\text { NPP } \\
\text { Overall }\end{array}$ \\
\hline Mathematics & .18 & $.28^{*}$ & .08 & .18 & $.25^{*}$ & .12 & $.24^{*}$ \\
\hline Language & .05 & $.29^{*}$ & .02 & .00 & .21 & -.05 & .10 \\
\hline History & .22 & $.24^{*}$ & -.02 & -.11 & $.27^{\star}$ & -.05 & .10 \\
\hline Arts & .07 & .14 & .00 & .08 & .13 & .02 & .04 \\
\hline
\end{tabular}

Note. ${ }^{\star}$ Significant at $p<.05$ level. NICOMACHUS Factors: Factor $1=$ Nurturing Values (items 1 - 9), Factor 2 = Strength Identification \& Boosting (items 10 - 14), Factor 3 = Parenting Context (items 15 - 17), Factor 4 = Involvement (items, 18 - 20). COMBINED 1 (Factors $1+2$ ) = Parenting of Positive Psychology Dimension, COMBINED 2 (Factors $3+4$ ) = Basic Needs Dimension.

NICOMACHUS factor scores for the NV, SIB, PC and I factors were $M=$ 4.30, $M=4.13, M=3.95$ and $M=4.18$ respectively. The overall NICOMACHUS had $M=4.14$. The $10^{\text {th }}, 25^{\text {th }}, 50^{\text {th }}, 75^{\text {th }}$, and $90^{\text {th }}$ percentile of the NICOMACHUS factor scores were calculated $(N=146)$. For NV, SIB, PC and I, $50 \%$ of the respondents had $M \leq 4.44, \leq 4.20, \leq 4.33$ and $\leq 4.33$ respectively. For the overall NICOMACHUS, $50 \%$ of the parents had $M \leq 4.28$ (Table 22). For each NICOMACHUS measured variable the highest mean was observed on item 13 $(M=4.60, S D=0.92)$ equivalent to Mostly True - Absolutely True Likert points. The lowest mean was observed on item $15(M=3.79, S D=1.41$. Table 22 lists the percentile means and Table 17 the measured variables means.

Finally, all the NICOMACHUS scale-level correlations were significant, $p$ $<.001$. The correlation between overall NICOMACHUS and NV, SIB, PC and I factor was $r_{\mathrm{S}}(144)=.70, .57, .74$ and .59 respectively $(p<.001)$. All the scale-level correlations are listed in Table 23.

\section{Study 3 Discussion}

The purpose of this study was: 1) to cross-validate the NICOMACHUS structure found in Study 2 in a different sample, 2) to reevaluate internal consistency reliability and factor-based reliability and convergent validity, 3) to examine convergent and discriminant validity with wellbeing and affect measures, 4) to examine the concurrent validity of NICOMACHUS with the child's school performance, 5) to re-calculate normative data for NICOMACHUS in a different sample.

The NICOMACHUS structure found in Study 2 contains 20 items in 4 correlated factors. A post hoc power analysis (see Wang, Watts, Anderson, \& Little, 2013) at the model level (MacCallum, Browne, \& Sugawara, 1996; Hancock \& Freeman, 2001) indicated that the sample used was 1.5 times larger than CFA required at $80 \%$ probability for rejecting a false null hypothesis (Cohen, 1988, 1992). To cross-validate this structure coming from EFA and CFA, a second 
Table 22. Percentiles of the NICOMACHUS/NPP factor scores (means).

\begin{tabular}{cccccccc}
\hline \multicolumn{5}{c}{ Sample $(N=\mathbf{1 4 6})$} & \multicolumn{5}{c}{ Percentile } \\
\hline Nicomachus factor & Mean & Range & $\mathbf{1 0}$ & $\mathbf{2 5}$ & $\mathbf{5 0}$ & $\mathbf{7 5}$ & $\mathbf{9 0}$ \\
\hline Factor 1-NV & 4.30 & $1.11-5.00$ & 3.56 & 4.03 & $\mathbf{4 . 4 4}$ & 4.78 & 4.89 \\
Factor 2-SIB & 4.13 & $1.4-5.00$ & 3.4 & 3.8 & $\mathbf{4 . 2 0}$ & 4.6 & 4.8 \\
Factor 3-PC & 3.95 & $1.00-5.00$ & 2.00 & 3.42 & $\mathbf{4 . 3 3}$ & 5.00 & 5.00 \\
Factor 4- I & 4.18 & $1.66-5.00$ & 3.33 & 3.67 & $\mathbf{4 . 3 3}$ & 4.67 & 5.00 \\
NPP (all 20 items) & 4.14 & $1.42-5.00$ & 3.53 & 3.95 & $\mathbf{4 . 2 8}$ & 4.52 & 4.73 \\
\hline
\end{tabular}

NICOMACHUS Factors: Factor 1 = Nurturing Values (items $1-9$ ), Factor $2=$ Strength Identification \& Boosting (items 10 - 14), Factor 3 = Parenting Context (items 15 - 17), Factor 4 = Involvement (items, 18 20).

Table 23. Scale-level correlations of the four NICOMACHUS/NPP factors and overall NICOMACHUS.

\begin{tabular}{lccccc}
\hline \multicolumn{1}{c}{$N=146$} & NV & SIB & PC & I & NPP \\
\hline Factor 1-Nurturing Values (NV) & - & & & & \\
Factor 2-Strength Identification \& Boosting (SIB) & $.49^{* *}$ & - & & & \\
Factor 3-Parenting Context (PC) & $.36^{* *}$ & $.21^{* *}$ & - & & \\
Factor 4-Involvement (I) & $.40^{* *}$ & $.19^{*}$ & $.18^{*}$ & - & \\
Overall NICOMACHUS/NPP & $.70^{* *}$ & $.57^{* *}$ & $.74^{* *}$ & $.59^{* *}$ & - \\
\hline
\end{tabular}

Note. ${ }^{*}$ Significant at $p<.001$ level. NICOMACHUS Factors: Factor 1 = Nurturing Values (items 1 - 9), Factor $2=$ Strength Identification \& Boosting (items 10 - 14), Factor 3 = Parenting Context (items 15 - 17), Factor 4 = Involvement (items, 18 - 20).

CFA was carried out in a new sample in Study 3. The four CFA models tested in Study 3 were parametrized identically with the four models tested in Study 2. The adequate fit of the 4 -factor model and of the 4 -factor model with two error covariances added was replicated. Thus, after taking into consideration: 1) the fit statistics, factor loadings, and factor correlations and 2) the cross-validation of error covariances added, the 4-factor model with error covariances seems to be $\mathrm{s}$ a reliable model. Error covariances were added in item 2 (I encourage my child to fight for what is fair) with item 3 ( $I$ incite my child to always tell the truth) and in item 13 (I encourage my child to study something related to his/her character strengths) with item 14 (I make sure that my child's extracurricular activities cultivate his/her character strengths). However, the model with error covariances is less parsimonious and must be revalidated further across time and more samples (Byrne, 2012; Brown, 2015). Power analysis at the model level (MacCallum, Browne, \& Sugawara, 1996; Hancock \& Freeman, 2001) indicated that the sample was 1.5:1 times larger than the required.

Internal consistency reliability for the overall NICOMACHUS was $>.90$ by all four coefficients calculated. Similarly, per factor reliability analysis showed results ranging from acceptable to very good (DeVellis, 2017), taking into account the length variability of the four factors (Kline, 1999; Nunally \& Bernstein, 1994) 
and the broadness of the parental construct (Elgar et al., 2007). Overall NICOMACHUS AVE also stayed in good levels (Fornell \& Larcker, 1981), considering the divergence of the parental construct, due to its broadness. The most noticeable findings were that: 1) all coefficients had comparable values across methods used ( $\alpha$ and $\omega)$; 2 ) all coefficients had comparable values across Studies (2 and 3).

Convergent and discriminant validity of NICOMACHUS with wellbeing and affect was evaluated using 11 scales and three affect scales coming from four wellbeing measures and an affect measure. The relationship of NICOMACHUS was highly significant with all wellbeing scales. The strongest relationship was observed between NICOMACHUS and PERMA Positive Emotions (Butler \& Kern, 2016) or NICOMACHUS with SWLS (Diener et al., 1985). SPANE-8 (Diener et al., 2009; Kyriazos et al., 2018b) was also significantly correlated with NICOMACHUS. About the factor correlations, NV and SIB were significantly correlated with all wellbeing scales except PERMA Relationships. Additionally, SIB was also non-significantly correlated with SWLS and PERMA Physical health $(\mathrm{H})$. PC factor was also highly correlated with all wellbeing measures except PERMA engagement (see more on engagement and marital status on Kyriazos et al., 2018c). I factor had a different pattern of relationships, i.e. non-significant correlations with all well-being and affect scales except PERMA Physical health. Generally, parenting has a negative effect on wellbeing. Specifically, wellbeing scores are lower to those who have children that those that do not (Hefferon \& Boniwell, 2011).

Finally, for the affect scales NV, SIB and PC had significant correlations with positive affect and non-significant with negative affect. I factor consistently showed a different relationship pattern. NICOMACHUS was significant correlated with both SPANE-8 positive and negative affect but not with PERMA negative emotion. Additionally, concurrent validity of NICOMACHUS with a child's school performance was also evaluated. Generally, the relationships were non-significant, with the exception of SIB factor with mathematics, and POPPD combined dimension with both history and mathematics.

\section{General Discussion}

The test development and validation process were completed in three phases (one per study). In Study 1, the test development process was described. Specifically, the theoretical model of positive psychology parenting was operationalized based on Seligman (2002), and subsequently existing parenting measures were reviewed. An initial pool was generated, listing items from: 1) existing parenting measures, 2) existing positive psychology measures potentially adaptable for parenting, 3) Newly generated items based on Authentic Happiness (Seligman, 2002) and 4) new items adapted for parenting from the Values in Action Inventory of Strengths for Youth (VIA Youth, Peterson \& Seligman, 2004; Park \& Peterson, 2006). This initial pool was refined and reduced repeatedly 3 times (see 
Table 6 and Figure 2), i.e. once based on test developers review, second based on the expert panel and focus group ratings and third based on item analysis and PCA data, after pilot testing.

During pilot testing, PCA was chosen over PAF because it is more appropriate for data reduction (Floyd \& Widaman, 1995; Steger et al., 2006). The version generated from pilot testing contained 20 items in 4 components, explaining more than two-thirds of the variance and had excellent internal consistency reliability, so it was not refined further. The next step was to validate newly developed NICOMACHUS on a large scale validation study (DeVellis, 2017; Kyriazos \& Stalikas, 2018b), i.e. Study 2.

Regarding the test specifications, the final pool did not contain reversed items, because literature is in disagreement regarding the effectiveness of reverse items (DeVellis, 2017; Brown, 2015). No filler items were included either. Regarding the reading ability of the items, they were written for the reading level of an 11 12 years of age (DeVellis, 2017). This is generally the reading level of a newspaper and a suggested standard (DeVellis, 2017). The items were rated on a five-point Likert scale $(1932,1952)$, from 1 = Absolutely Untrue, 2 = Mostly Untrue, 3 = Can't Say True or Untrue, $4=$ Mostly True, 5 = Absolutely True because it is generally considered more appropriate for self-report instruments and it is preferable over other alternatives (Clark \& Watson, 1995; Singh et al., 2016). Furthermore, it is the most widely used scaling both in parenting measures and in general (Dimitrov, 2012; Barker et al., 2016)—specially when the Classical Test Theory method is used for the test development as in this case (DeVellis, 2017).

A large scale validation study followed (Study 2) with the following goals: 1) to examine construct validity with EFA and CFA;2) to assess measurement invariance across child gender; 3 ) to calculate internal consistency reliability ( $\alpha$, Cronbach, 1951) and model-based reliability ( $\omega$; Bollen, 1980; Bentler, 1972, 2009; McDonald, 1999); 4) to examine model-based convergent validity (AVE; Fornell \& Larcker, 1981); 5) to evaluate the convergent and discriminant validity with positive and non-positive parenting scales respectively (Elgar, et al., 2007; Reid et al., 2015; James et al., 1985; Lovejoy et al., 1999; Sheppard, 2010; Berry \& Jones, 1995); 6) to calculate normative data.

After the large scale validation of NICOMACHUS a cross-validating Study was carried out (Study 3). The goals of Study 3 were as follows: 1) to cross-validate the NICOMACHUS structure found in Study 2 in a different sample, 2) to reevaluate internal consistency reliability ( $\alpha$, Cronbach, 1951), 3) to reevaluate reliability ( $\omega$; Bollen, 1980; Bentler, 1972, 2009; McDonald, 1999) and convergent validity (AVE; Fornell \& Larcker, 1981) at the model level (see Mair, 2018; Sha \& Ackerman, 2018), 4) to examine the convergent and discriminant validity with wellbeing and affect scales (Butler \& Kern, 2016; Keyes et al., 2008; Diener, et al., 1985; Lyubomirsky \& Lepper, 1999; Diener et al., 2009; Kyriazos et al., 2018b), 5) to examine the concurrent validity of NICOMACHUS with the child's school performance in four learning fields, 6) to re-calculate normative 
data for NICOMACHUS in a different sample.

The sample in all three studies was recruited using a variation of the network sampling method, with the difference that those who recruited volunteers did not participate in the sample themselves. For a description of the method see APA (2014) as well as Stalikas and Kyriazos (2019).

Regarding construct validity, both in the validation (Study 2) and the cross-validation study (Study 3) the emerging factor structure was consistently supported with no cross-loadings and four clearly formulated factors. Note also that even in the PC, carried out during piloting four components emerged. Crucially, both in PCA and EFA the components/factors explained about two-thirds of the total variance corroborating each other. The four EFA factors were Nurturing Values (NV, items 1 - 9), Strength Identification and Boosting (SIB, items 10 - 14), Parenting Context (PC, items 15 - 17) and Involvement (I, items 18 20). By merging NV and SIB we get the theoretical dimension (Seligman, 2002) we termed Parenting of Positive Psychology. By unifying PC and I we get the theoretical dimension we called of Basic Needs Satisfaction (Maslow, 1975; Bradley, 2002; Ryan \& Deci, 2000). The highest factor inter-correlations were observed between NV-SIB, and NV-I.

The two CFAs that followed EFA (one in Study 2 and one in Study 3) supported the evidence of construct validity further. The four-factor model had adequate fit in both CFAs. The multiple-assessment approach was adopted for the fit evaluation (Bentler \& Bonett, 1980), because it is more conservative (Brown, 2015). Moreover, the range of CFA loadings and CFA factor inter-correlations was satisfactory and comparable across the two CFA studies, again corroborating each other. Consistently, the factor inter-correlations between NV-SIB, and NV-I were the highest, replicating the pattern observed in preceding EFA (Study 2).

Moreover, the four-factor model with two error covariances was cross-validated, evidencing the model stability and validity (Cudeck \& Browne, 1983; MacCallum \& Austin, 2000; Boomsma, 2000) but the solution is less parsimonious in comparison to the four-factor model without error covariances. The items that were specified to covary ("I encourage my child to fight for what is fair" X "I incite my child to always tell the truth" and "I encourage my child to study something related to his/her character strengths" $\times$ "I make sure that my child's extracurricular activities cultivate his/her character strengths") are semantically and logically connected. Generally, error covariances are regarded as an overfitting practice when 1) theoretically unfounded or 2) semantically unrelated, 3) not cross-validated (Byrne, 2012; Brown, 2015). However, in this case there is content overlap and cross-validation was carried out, thus error covariances are acceptable (see Kyriazos \& Stalikas, 2018b). At the same time, the power analysis suggested that the sample sizes were sufficient in all studies, and offering additional reliability to the structure that arose (see Kaplan, 1995; Saris \& Satorra, 1993; Boomsma, 2000).

Furthermore, NICOMACHUS measurement invariance across child gender 
was also examined in Study 2 using the four-factor model as a baseline model (no error covariances). Full measurement invariance to the strict level was established successfully, i.e. the strictest possible measurement invariance test (Wang \& Wang, 2012). Thus, factor structure, factor loadings, indicator means and indicator residuals can be safely compared between parents either caring for a girl or a boy.

Concerning the internal consistency reliability, model-based reliability (Mair, 2018) and convergent validity at the model level for NICOMACHUS, multiple methods were calculated (Cronbach, 1951; Bollen, 1980; Bentler, 1972, 2009; McDonald, 1999) because of the reliability coefficient is considered to be one of the most important indicators of scale quality (DeVellis, 2017). However, Cronbach's alpha may generate inaccurate results in multidimensional constructs (Sha \& Ackerman, 2018). The internal consistency reliability and factor-based reliability of NICOMACHUS were excellent and stable across methods and samples corroborating each other. Generally, coefficients $>.90$ are considered excellent (DeVellis, 2017; Hair et al., 2010; Nunnally \& Bernstein, 1994). However, for broad constructs like parenting these levels of reliability are uncommonly high (e.g., Frick et al., 1999; Elgar et al., 2007; Boyle, 1991), especially taking into account the sensitivity of the alpha coefficient to the number of items (Kline, 1999; Green, Lissitz, \& Mulaik, 1977; Nunnally \& Bernstein, 1994).

The convergent and discriminant validity of NICOMACHUS were evaluated using 1) Positive parenting and Non-Positive parenting practices scales (Elgar et al., 2007; Reid et al., 2015; James et al., 1985; Lovejoy et al., 1999; Berry \& Jones, 1995; Sheppard, 2010); 2) Wellbeing and affect scales (Butler \& Kern, 2016; Keyes et al., 2008; Diener et al., 1985; Lyubomirsky \& Lepper, 1999; Diener et al., 2009; Kyriazos, et al., 2018b) and 3) Child's school performance (in Mathematics, Language, History, and Arts). Generally, a clear pattern of highly significant relationships emerged between NICOMACHUS and Positive Parenting Practices Scales, especially with Supportive/Engaged Parenting (Lovejoy et al., 1999), Emotional Warmth (Reid et al., 2015) and Positive Parenting Themes (Berry \& Jones, 1995). Generally, these parenting scales are supportive parenting practices that in tandem with Emotional Warmth (i.e. positive emotion, Seligman, 2002; Fredrickson, 1998, 2001) belong to the facet of responsive parenting (Baumrind, 1989; Maccoby \& Martin, 1983; Reid et al., 2015). The Non-Positive Parenting Practices Scales were also significant related but in lower magnitude and consistency. Lewis (1981) proposed that responsive parenting is more important than parental control (an inherently non-positive parenting) in supporting positive parenting outcomes (cited in Reid et al., 2015).

The convergent and discriminant validity of NICOMACHUS with Wellbeing and affect scales was also evidenced by highly significant relationships of moderate magnitude with wellbeing scales like PERMA Positive emotion (Butler \& Kern, 2016), Satisfaction with Life Scale (Diener et al., 1985), MHC-SF psychological wellbeing (Keyes et al., 2008), and Positive affect (SPANE-8 Positive Experiences (Diener et al., 2009; Kyriazos et al., 2018b). This is a supporting evi- 
dence of the hypothesis postulated in the theoretical model of NICOMACHUS those positive emotions fuel the identification and boosting of strengths (Seligman, 2002). Actually, retrospective studies of parental behavior (Huta, 2012) suggest that responsive-demanding parents (Baumrind, 1989; Maccoby \& Martin, 1983) that either verbally endorsed eudaimonia (Ryan \& Deci, 2001; Huta \& Ryan, 2010) or role modeled it (e.g. Bandura, 1977), have youngsters seeking eudaimonic activities. However, well-being from these eudaimonic activities was achieved only if parents were acting as eudaimonic role-models, not by simply endorsing it verbally. A similar pattern was present for hedonic activities (Ryan \& Deci, 2001; Huta \& Ryan, 2010) and well-being achieved from them (Huta, 2012). These patterns of parental influence in child's wellbeing are in agreement with the highly significant relationship observed not only between NICOMACHUS and the Positive Parenting Practices Scales (Elgar et al., 2007; Reid et al., 2015; James et al., 1985; Lovejoy et al., 1999; Berry \& Jones, 1995) but with PERMA Positive emotion (Butler \& Kern, 2016) and life satisfaction (Diener et al., 1985).

About the strength of the associations found in both studies: 1) Generally, almost all relationships were of low to moderate magnitude. The strength of associations is discussed in parenting literature (e.g. Seabridge, 2014; Hershkowitz et al., 2017; Burlaka et al., 2017). 2) Crucially, NICOMACHUS was highly significantly correlated with all parenting, wellbeing and affect measures, and significance is more important in small samples, than the magnitude of the relationships (Mayers, 2013).

Finally, regarding the relationship of NICOMACHUS with a child's school performance, the only significant relationships observed were between the overall NICOMACHUS and good performance in Mathematics. SIB factor was also significantly related to good performance in all cognitive demanding fields like (in order of magnitude of the relationship) Language, Mathematics and History but not with less demanding like arts. Note that all significant relationships were observed in fields that generally are time-consuming for parents when supervising child's homework, and maybe during this process strengths identification and boosting is most relevant and important.

\section{Conclusion}

The initial validation of NICOMACHUS offered promising evidence of validity and reliability, because all findings had acceptable magnitude, stability and consistency across methods (PCA, EFA, CFA and measurement invariance) and samples. Taking into consideration the joint findings from the three studies, construct validity was fully supported, because a consistent structure of four factors emerged in all studies (piloting, validating and cross-validating), with robust loadings, and a stable pattern of factor inter-correlations. The internal consistency reliability was equally promising, achieving excellent levels (>.90) across methods and samples. The convergent and discriminant validity was suc- 
cessfully supported too, by a highly significant, clear pattern of relationships, especially between NICOMACHUS and positive parenting practices, well-being and positive affect.

Conclusively, considering jointly all the above findings NICOMACHUS is a valid and reliable tool for parents of children aged 7 - 13 years. However, validity is a property continuously assessed in the long-term, with other constructs like meaning in life (see Stalikas et al., 2018) or resilience (see Kyriazos et al., 2018c, 2018d). Thus, the truly promising psychometric profile of NICOMACHUS requires further validation in the future to be supported further in different samples and cultures.

A limitation of the study is the inherent weaknesses of self report measures. A second limitation is the use of more mothers than fathers in all three samples. Third, the Likert scale used was in the agreed-disagreed format, while other parenting measures contain a frequency scale to overcome some weaknesses of self report bias. However this scale was incompatible with the items of NPP. Finally no reverse items were included because of the controversy about them (e.g. DeVellis, 2017).

Future directions include the validation of NPP in different groups (e.g. parents of adolescents). Also useful would be specifying different models for mothers and fathers to examine the structure in variance (see Elgar et al., 2007) as this wasn't a gender balanced sample.

In the meanwhile NPP is a valid and reliable tool for parenting practices for the Greek Cultural Context.

The questionnaire is available in Appendix (translated in English, although the validation was carried out in a Greek version).

\section{Conflicts of Interest}

The authors declare no conflicts of interest regarding the publication of this paper.

\section{References}

Ainsworth, M. D. S., Blehar, M. C., \& Waters, E. (1978). Patterns of Attachment: A Psychological Study of the Strange Situation. Hillsdale, NJ: Earlbaum.

Akaike, H. (1987). Factor Analysis and AIC. Psychometrika, 52, 317-332. https://doi.org/10.1007/BF02294359

American Psychological Association (APA) (2014). APA Dictionary of Statistics and Research Methods. Washington DC: Author.

Bandura, A. (1977). Social Learning Theory. Englewood Cliffs, NJ: Prentice-Hall.

Barker, C., Pistrang, N., \& Elliott, R. (2016). Research Methods in Clinical Psychology: An Introduction for Students and Practitioners (3rd ed.). Oxford: John Wiley \& Sons, Ltd.

Barry, C. L., \& Finney, S. J. (2008). A Psychometric Investigation of the College Self-Efficacy Inventory. Harrisonburg, VA: Center for Assessment and Research Studies, James Madison University.

Bartlett, M. S. (1954). A Note on the Multiplying Factors for Various Chi Square Ap- 
proximations. Journal of the Royal Statistical Society (Series B), 16, 296-298.

https://doi.org/10.1111/j.2517-6161.1954.tb00174.x

Baumrind, D. (1989). Rearing Competent Children. In W. Damon (Ed.), Child Development Today and Tomorrow (pp. 349-378). San Francisco, CA: Jossey-Bass.

Belsky, J. (1984). The Determinants of Parenting: A Process Model. Child Development, 5, 83-96.

Bentler, P. M. (1972). A Lower-Bound Method for the Dimension-Free Measurement of Internal Consistency. Social Science Research, 1, 343-357. https://doi.org/10.1016/0049-089X(72)90082-8

Bentler, P. M. (1990). Comparative Fit Indexes in Structural Models. Psychological Bulletin, 107, 238-246. https://doi.org/10.1037/0033-2909.107.2.238

Bentler, P. M. (2009). Alpha, Dimension-Free, and Model-Based Internal Consistency Reliability. Psychometrika, 74, 137-143. https://doi.org/10.1007/s11336-008-9100-1

Bentler, P. M., \& Bonett, D. G. (1980). Significance Tests and Goodness of Fit in the Analysis of Covariance Structures. Psychological Bulletin, 88, 588-606. https://doi.org/10.1037/0033-2909.88.3.588

Berry, J. D., \& Jones, W. H. (1995). The Parental Stress Scale: Initial Psychometric Evidence. Journal of Social and Personal Relationships, 12, 463-472. https://doi.org/10.1177/0265407595123009

Bollen, K. A. (1980). Issues in the Comparative Measurement of Political Democracy. American Sociological Review, 45, 370-390. https://www.jstor.org/stable/2095172 https://doi.org/10.2307/2095172

Boniwell, I. (2012). Positive Psychology in a Nutshell: The Science of Happiness (3rd ed.). London: McGraw-Hill Education.

Boomsma, A. (2000). Reporting Analyses of Covariance Structure. Structural Equation Modeling, 7, 461-483. https://doi.org/10.1207/S15328007SEM0703_6

Bowlby, J. (1969). Attachment and Loss: Attachment (Vol. 1, Pelican ed.). London: Penguin.

Bowlby, J. (1973). Attachment and Loss, Vol. 2: Separation. New York: Basic Books.

Boyle, G. J. (1991). Does Item Homogeneity Indicate Internal Consistency or Item Redundancy in Psychometric Scales? Personality and Individual Differences, 12, 291-294. https://doi.org/10.1016/0191-8869(91)90115-R

Bradley, R. H. (2002). Environment and Parenting. In Handbook of Parenting: Vol. 2: Biology and Ecology of Parenting (2nd ed., pp. 281-314). Mahwah, NJ: Lawrence Erlbaum Associates.

Bradley, R. H., \& Caldwell, B. M. (1995). Caregiving and the Regulation of Child Growth and Development: Describing Proximal Aspects of Caregiving Systems. Developmental Review, 15, 38-85. https://doi.org/10.1006/drev.1995.1002

Brown, T. A. (2015). Confirmatory Factor Analysis for Applied Research (2nd ed.). New York: Guilford Publications.

Browne, M. W., \& Cudeck, R. (1993). Alternative Ways of Assessing Model Fit. In K. A. Bollen, \& J. S. Long (Eds.), Testing Structural Equation Models (pp. 136-162). Newbury Park, CA: Sage.

Burlaka, V., Graham-Bermannb, S. A., \& Delvac, J. (2017). Family Factors and Parenting in Ukraine. Child Abuse \& Neglect, 72, 154-162.

https://doi.org/10.1016/j.chiabu.2017.08.007

Butler, J., \& Kern, M. L. (2016). The PERMA-Profiler: A Brief Multidimensional Measure 
of Flourishing. International Journal of Wellbeing, 6, 1-48. https://doi.org/10.5502/ijw.v6i3.526

Byrne, B. M. (2012). Structural Equation Modeling with Mplus: Basic Concepts, Applications, and Programming. London: Routledge. https://doi.org/10.4324/9780203807644

Cattell, R. (1978). The Scientific Use of Factor Analysis. New York: Plenum. https://doi.org/10.1007/978-1-4684-2262-7

Chen, F. F. (2007). Sensitivity of Goodness of Fit Indexes to Lack of Measurement Invariance. Structural Equation Modeling, 14, 464-504. https://doi.org/10.1080/10705510701301834

Cheung, G. W., \& Rensvold, R. B. (2002). Evaluating Goodness-of-Fit Indexes for Testing Measurement Invariance. Structural Equation Modeling, 9, 233-255. https://doi.org/10.1207/S15328007SEM0902_5

Clark, L. A., \& Watson, D. (1995). Constructing validity: Basic Issues in Objective Scale Development. Psychological Assessment, 7, 309. https://doi.org/10.1037/1040-3590.7.3.309

Cohen, J. (1988). Statistical Power Analysis for the Behavioral Sciences (2nd ed). Hillsdale, NJ: Lawrence Erlbaum.

Cohen, J. (1992). A Power Primer. Psychological Bulletin, 112, 155-159. https://doi.org/10.1037/0033-2909.112.1.155

Conoley, C. W., \& Conoley, J. C. (2009). Positive Psychology and Family Therapy. Hoboken, NJ: Wiley.

Conoley, C. W., Conoley, J. C., \& Pontrelli, M. E. (2014). Positive Family Therapy Interventions. In A. C. Parks, \& S. M. Schueller (Eds.), The Wiley Blackwell Handbook of Positive Psychological Interventions (pp. 233-254). Hoboken, NJ: John Wiley \& Sons. https://doi.org/10.1002/9781118315927.ch13

Costello, A. B., \& Osborne, J. (2005). Best Practices in Exploratory Factor Analysis: Four Recommendations for Getting the Most from Your Analysis. Practical Assessment Research \& Evaluation, 10, 1-9.

Cronbach, L. J. (1951). Coefficient Alpha and the Internal Structure of Tests. Psychometrika, 16, 297-334. https://doi.org/10.1007/BF02310555

Csikszentmihalyi, M. (1990). Flow: The Psychology of Optimal Experience. New York, NY: Harper Perennial.

Cudeck, R., \& Browne, M. W. (1983). Cross-Validation of Covariance Structures. Multi-Variate Behavioral Research, 18, 147-167. https://doi.org/10.1207/s15327906mbr1802_2

Curran, P. J., West, S. G., \& Finch, J. F. (1996). The Robustness of Test Statistics to Non-Normality and Specification Error in Confirmatory Factor Analysis. Psychological Methods, 1, 16. https://doi.org/10.1037/1082-989X.1.1.16

DeVellis, R. F. (2017). Scale Development: Theory and Applications (4th ed.). Thousand Oaks, CA: Sage.

Diener, E., \& Seligman, M. E. (2004). Beyond Money: Toward an Economy of Well-Being. Psychological Science in the Public Interest, 5, 1-31. https://doi.org/10.1111/j.0963-7214.2004.00501001.x

Diener, E., Emmons, R. A., Larsen, R. J., \& Griffin, S. (1985). The Satisfaction with Life Scale. Journal of Personality Assessment, 49, 71-75. https://doi.org/10.1207/s15327752jpa4901_13 
Diener, E., Wirtz, D., Tov, W., Kim-Prieto, C., Choi, D. W., Oishi, S. et al. (2009). New Well-Being Measures: Short Scales to Assess Flourishing and Positive and Negative Feelings. Social Indicators Research, 97, 143-156. https://doi.org/10.1007/s11205-009-9493-y

Dimitrov, D. M. (2012). Statistical Methods for Validation of Assessment Scale Data in Counseling and Related Fields. Alexandria, VA: American Counseling Association.

Doornik, J. A., \& Hansen, H. (2008). An Omnibus Test for Univariate and Multivariate Normality. Oxford Bulletin of Economics and Statistics, 70, 927-939. https://doi.org/10.1111/j.1468-0084.2008.00537.x

Durrant, J. (2011). Positive Discipline: What It Is and How to Do It (2nd ed.). Sweden: Save the Children Sweden.

Elgar, F. J., Waschbusch, D. A., Dadds, M. R., \& Sigvaldason, N. (2007). Development and Validation of a Short Form of the Alabama Parenting Questionnaire. Journal of Child and Family Studies, 16, 243-259. https://doi.org/10.1007/s10826-006-9082-5

Epskamp, S. (2019). R Package semPlot v1.1.1.

Field, A. (2005). Discovering Statistics Using SPSS (2nd ed.). London: Sage.

Finney, S. J., \& DiStefano, C. (2006). Nonnormal and Categorical Data in Structural Equation Models. In G. R. Hancock, \& R. O. Mueller (Eds.), A Second Course in Structural Equation Modeling (pp. 269-314). Greenwich, CT: Information Age.

Floyd, F. J., \& Widaman, K. F. (1995). Factor Analysis in the Development and Refinement of Clinical Assessment Instruments. Psychological Assessment, 7, 286-299. https://doi.org/10.1037/1040-3590.7.3.286

Ford, D. H., \& Lerner, R. M. (1992). Developmental Systems Theory: An Integrative Approach. Thousand Oaks, CA: Sage Publications, Inc.

Fornell, C., \& Larcker, D. F. (1981). Structural Equation Models with Unobservable Variables and Measurement Error: Algebra and Statistics. Journal of Marketing Research, 18, 382-388. https://doi.org/10.1177/002224378101800313

Fredrickson, B. (2009). Positivity: Groundbreaking Research Reveals How to Embrace the Hidden Strength of Positive Emotions, Overcome Negativity, and Thrive. New York: Crown.

Fredrickson, B. L. (1998). Cultivated Emotions: Parental Socialization of Positive Emotions and Self-Conscious Emotions. Psychological Inquiry, 9, 279-281. https://doi.org/10.1207/s15327965pli0904_4

Fredrickson, B. L. (2001). The Role of Positive Emotions in Positive Psychology: The Broaden-and-Build Theory of Positive Emotions. American Psychologist, 56, 218-226. https://doi.org/10.1037/0003-066X.56.3.218

Fredrickson, B. L., \& Losada, M. F. (2005). Positive Affect and the Complex Dynamics of Human Flourishing. American Psychologist, 60, 678-686. https://doi.org/10.1037/0003-066X.60.7.678

Frick, P. J. (1991). The Alabama Parenting Questionnaire. Unpublished Rating Scale, Tuscaloosa, AL: University of Alabama. https://doi.org/10.1037/t58031-000

Frick, P. J., Christian, R. E., \& Wootton, J. M. (1999). Age Trends in the Association between Parenting Practices and Conduct Problems. Behavior Modification, 23, 106-128. https://doi.org/10.1177/0145445599231005

Gable, S. L., \& Haidt, J. (2005). What (and Why) Is Positive Psychology? Review of General Psychology, 9, 103-110. https://doi.org/10.1037/1089-2680.9.2.103

Green, S. B., Lissitz, R. W., \& Mulaik, S. A. (1977). Limitations of Coefficient Alpha as an 
Index of Test Unidimensionality. Educational and Psychological Measurement, 37, 827-836. https://doi.org/10.1177/001316447703700403

Guadagnoli, E., \& Velicer, W. F. (1988). Relation to Sample Size to the Stability of Component Patterns. Psychological Bulletin, 103, 265. https://doi.org/10.1037/0033-2909.103.2.265

Hair, J., Black, W., Babin, B., \& Anderson, R. (2010). Multivariate Data Analysis (7th ed.). Upper Saddle River, NJ: Prentice-Hall, Inc

Hancock, G. R., \& Freeman, M. J. (2001). Power and Sample Size for the Root Mean Square Error of Approximation of Not Close Fit in Structural Equation Modeling. Educational and Psychological Measurement, 61, 741-758. https://doi.org/10.1177/00131640121971491

Harman, H. H. (1962). Modern Factor Analysis (2nd ed.). Chicago, IL: University of Chicago Press.

Hefferon, K., \& Boniwell, I. (2011). Positive Psychology: Theory, Research and Applications. New York: McGraw-Hill Education.

Henze, N., \& Zirkler, B. (1990). A Class of Invariant Consistent Tests for Multivariate Normality. Communications in Statistics: Theory and Methods, 19, 3595-3617. https://doi.org/10.1080/03610929008830400

Hershkowitz, M., Dekel, R., Fridkin, S., \& Freedman, S. (2017). Posttraumatic Stress Disorder, Parenting, and Marital Adjustment among a Civilian Population. Frontiers in Psychology, 8, 1655. https://doi.org/10.3389/fpsyg.2017.01655

Horn, J. L. (1965). A Rationale and Test for the Number of Factors in Factor Analysis. Psychometrika, 30, 179-185. https://doi.org/10.1007/BF02289447

Howard, J., Gagné, M., Morin, A. J. S., Wang, Z. N., \& Forest, J. (2016). Using Bifactor Exploratory Structural Equation Modeling to Test for a Continuum Structure of Motivation. Journal of Management, 44, 2638-2664.

Hu, L. T., \& Bentler, P. M. (1999). Cutoff Criteria for Fit Indexes in Covariance Structure Analysis: Conventional Criteria versus New Alternatives. Structural Equation Modeling, 6, 1-55. https://doi.org/10.1080/10705519909540118

Huta, V. (2012). Linking Peoples' Pursuit of Eudaimonia and Hedonia with Characteristics of Their Parents: Parenting Styles, Verbally Endorsed Values, and Role Modeling. Journal of Happiness Studies, 13, 47-61. https://doi.org/10.1007/s10902-011-9249-7

Huta, V., \& Ryan, R. M. (2010). Pursuing Pleasure or Virtue: The Differential and Overlapping Well-Being Benefits of Hedonic and Eudaimonic Motives. Journal of Happiness Studies, 11, 735-762. https://doi.org/10.1007/s10902-009-9171-4

Jackson, D. N. (1970). A Sequential System for Personality Scale Development. In C. D. Spielberger (Ed.), Current Topics in Clinical and Community Psychology (Vol. 2, pp. 61-96). New York: Academic Press. https://doi.org/10.1016/B978-0-12-153502-5.50008-4

Jahoda, M. (1958). Joint Commission on Mental Health and Illness Monograph Series: Vol. 1. Current Concepts of Positive Mental Health. New York: Basic Books. https://doi.org/10.1037/11258-000

James, D., Schumm, W., Kennedy, C., Grigsby, C., Shectman, K., \& Nichols, C. (1985). Characteristics of the Kansas Parental Satisfaction Scale among Two Samples of Married Parents. Psychological Reports, 57, 163-169.

https://doi.org/10.2466/pr0.1985.57.1.163

Jang, E. E., \& Roussos, L. A. (2007). An Investigation into the Dimensionality of TOEFL 
Using Conditional Covariance-Based Nonparametric Approach. Journal of Educational Measurement, 44, 1-21. https://doi.org/10.1111/j.1745-3984.2007.00024.x

Jorgensen, T. (2019). R Package SemTools v0.5-1.

Kaiser, H. (1970). A Second Generation Little Jiffy. Psychometrika, 35, 401-415. https://doi.org/10.1007/BF02291817

Kaiser, H. F. (1974). An Index of Factorial Simplicity. Psychometrika, 39, 31-36. https://doi.org/10.1007/BF02291575

Kaplan, D. (1995). Statistical Power in Structural Equation Modeling. In R. H. Hoyle (Ed.), Structural Equation Modeling: Concepts, Issues, and Applications (pp. 100-117). Thousand Oaks, CA: Sage.

Kelley, T. L. (1935). Essential Traits of Mental Life, Harvard Studies in Education (Vol. 26). Cambridge, MA: Harvard University Press.

Keyes, C. L. (2002). The Mental Health Continuum: From Languishing to Flourishing in Life. Journal of Health and Social Behavior, 43, 207-222. https://doi.org/10.2307/3090197

Keyes, C. L. M., Wissing, M., Potgieter, J., Temane, M., Kruger, A., \& van Rooy, S. (2008). Evaluation of the Mental Health Continuum-Short Form (MHC-SF) in Setswana-Speaking South Africans. Clinical Psychology and Psychotherapy, 15, 181-192. https://doi.org/10.1002/cpp.572

Kline, P. (1999). Handbook of Psychological Testing. London: Routledge.

Kline, R. B. (2010). Principles and Practice of Structural Equation Modeling (3th ed.). New York: The Guilford Press.

Kline, R. B. (2016). Principles and Practice of Structural Equation Modeling (4th ed.). New York: The Guilford Press.

Korkmaz, S. (2019). MVN 5.7: An R Package for Assessing Multivariate Normality ( $R$ Package). Edirne: Trakya University.

Kuhn, M. (2019). R Package Caret V.6.0-84.

Kyriazos, T. A., \& Stalikas, A. (2018a). Positive Parenting or Positive Psychology Parenting? Towards a Conceptual Framework of Positive Psychology Parenting. Psychology, 9, 1761-1788. https://doi.org/10.4236/psych.2018.97104

Kyriazos, T. A., \& Stalikas, A. (2018b). Applied Psychometrics: The Steps of Scale Development and Standardization Process. Psychology, 9, 2531-2560. https://doi.org/10.4236/psych.2018.911145

Kyriazos, T. A., \& Stalikas, A. (2019a). Alabama Parenting Questionnaire-Short Form (APQ-9): Evidencing Construct Validity with Factor Analysis, CFA MTMM and Measurement Invariance in a Greek Sample. Psychology, 10, 1790-1817.

https://doi.org/10.4236/psych.2019.1012117

Kyriazos, T. A., \& Stalikas, A. (2019b). Validation of the Greek Version of the Parenting Behaviours and Dimensions Questionnaire (PBDQ). Under Preparation.

Kyriazos, T. A., \& Stalikas, A. (2019c). Validation of the Kansas Parental Satisfaction Scale (KPSS) in a Greek Sample. Under Preparation.

Kyriazos, T. A., \& Stalikas, A. (2019d). Validation of the Greek Version of the Parent Behavior Inventory (PBI). Under Preparation.

Kyriazos, T. A., \& Stalikas, A. (2019e). Validation of the Greek Version of the Parent Concerns Questionnaire (PCQ). Under Preparation.

Kyriazos, T. A., \& Stalikas, A. (2019f). Validation of the Greek Version of the Parental Stress Scale (PSS). Under Preparation. 
Kyriazos, T. A., Stalikas, A., Prassa, K., \& Yotsidi, V. (2018b). A 3-Faced Construct Validation and a Bifactor Subjective Well-Being Model Using the Scale of Positive and Negative Experience, Greek Version. Psychology, 9, 1143-1175. https://doi.org/10.4236/psych.2018.95071

Kyriazos, T. A., Stalikas, A., Prassa, K., Galanakis, M., Flora, K., \& Chatzilia, V. (2018c). The Flow Short Scale (FSS) Dimensionality and What MIMIC Shows on Heterogeneity and Invariance. Psychology, 9, 1357-1382. https://doi.org/10.4236/psych.2018.96083

Kyriazos, T. A., Stalikas, A., Prassa, K., Galanakis, M., Yotsidi, V., \& Lakioti, A. (2018d). Psychometric Evidence of the Brief Resilience Scale (BRS) and Modeling Distinctiveness of Resilience from Depression and Stress. Psychology, 9, 1828-1857.

https://doi.org/10.4236/psych.2018.97107

Lamers, S. M. A., Westerhof, G. J., Bohlmeijer, E. T., ten Klooster, P. M., \& Keyes, C. L. M. (2011). Evaluating the Psychometric Properties of the Mental Health Continuum-Short Form (MHC-SF). Journal of Clinical Psychology, 67, 99-110. https://doi.org/10.1002/jclp.20741

Lerner, R. M., Rothbaum, F., Boulos, S., \& Castellino, D. R. (2002). Developmental Systems Perspective on Parenting. In M. H. Bornstein (Ed.), Handbook of Parenting: Biology and Ecology of Parenting (pp. 315-344). Mahwah, NJ: Lawrence Erlbaum Associates Publishers.

Lewis, C. C. (1981). The Effects of Parental Firm Control: A Reinterpretation of Findings. Psychological Bulletin, 90, 547-563. https://doi.org/10.1037/0033-2909.90.3.547

Likert, R. (1932). A Technique for the Measurement of Attitudes. Archives of Psychology, 22, 55.

Likert, R. A. (1952). A Technique for the Development of Attitude Scales. Educational and Psychological Measurement, 12, 313-315.

Linley, P. A., \& Joseph, S. (2015). Positive Psychology in Practice (2nd ed.). Hoboken, NJ: Wiley.

Lorezo-Seva, U., \& Ferrando, J. P. (2013). Factor v.9.20 Computer Software. Tarragona: Authors.

Lovejoy, M. C., Weis, R., O’Hare, E., \& Rubin, E. C. (1999). Development and Initial Validation of the Parent Behaviour Inventory. Psychological Assessment, 11, 534-545. https://doi.org/10.1037/1040-3590.11.4.534

Lyubomirsky, S., \& Lepper, H. (1999). A Measure of Subjective Happiness: Preliminary Reliability and Construct Validation. Social Indicators Research, 46, 137-155. https://doi.org/10.1023/A:1006824100041

MacCallum, R. C., \& Austin, J. T. (2000). Applications of Structural Equation Modeling in Psychological Research. Annual Review of Psychology, 51, 201-226. https://doi.org/10.1146/annurev.psych.51.1.201

MacCallum, R. C., Browne, M. W., \& Sugawara, H. M. (1996). Power Analysis and Determination of Sample Size for Covariance Structure Modeling. Psychological Methods, 1, 130. https://doi.org/10.1037/1082-989X.1.2.130

Maccoby, E. E., \& Martin, J. A. (1983). Socialization in the Context of the Family: Parent-Child Interaction. In P. H. Mussen, \& E. M. Hetherington (Eds.), Handbook of Child Psychology: Vol. 4. Socialization, Personality, and Social Development (4th ed., pp. 1-101). New York: Wiley.

Mahalanobis, P. C. (1936). On the Generalized Distance in Statistics. Proceedings of the National Institute of Science, India, 12, 49-55.

Mair, P. (2018). Modern Psychometrics with R. Cham: Springer International. 
https://doi.org/10.1007/978-3-319-93177-7

Mardia, K. V. (1970). Measures of Multivariate Skewness and Kurtosis with Applications. Biometrika, 57, 519-530. https://doi.org/10.1093/biomet/57.3.519

Marsh, H. W., Morin, A. J. S., Parker, P. D., \& Kaur, G. (2014). Exploratory Structural Equation Modeling: An Integration of the Best Features of Exploratory and Confirmatory Factor Analysis. Annual Review of Clinical Psychology, 10, 85-110. https://doi.org/10.1146/annurev-clinpsy-032813-153700

Maslow, A. H. (1975). Motivation and Personality. London: Harper \& Row.

Mayers, A. (2013). Introduction to Statistics and SPSS in Psychology. Harlow: Pearson Education.

McDonald, R. P. (1999). Test Theory: A Unified Treatment. Mahwah, NJ: Erlbaum.

Mitchell, J., Vella-Brodrick, D., \& Klein, B. (2010). Positive Psychology and the Internet: A Mental Health Opportunity. Electronic Journal of Applied Psychology, 6, 30-41. https://doi.org/10.7790/ejap.v6i2.230

Morton, K. L., Barling, J., Rhodes, R. E., Mâsse, L. C., Zumbo, B. D., \& Beauchamp, M. R. (2011). The Application of Transformational Leadership Theory to Parenting Questionnaire Development and Implications for Adolescent Self-Regulatory Efficacy and Life Satisfaction. Journal of Sport \& Exercise Psychology, 33, 688-709.

https://doi.org/10.1123/jsep.33.5.688

Nelsen, J. (2006). Positive Discipline. New York: Random House.

Nitsch, E., Hannon, G., Rickard, E., Houghton, S., \& Sharry, J. (2015). Positive Parenting: A Randomized Controlled Trial Evaluation of the Parents Plus Adolescent Programme in Schools. Child and Adolescent Psychiatry and Mental Health, 9, 43.

https://doi.org/10.1186/s13034-015-0077-0

Nunnally, J. C., \& Bernstein, I. H. (1994). Psychometric Theory(3rd ed.). New York, NY: McGraw-Hill.

Oremus, M., Cosby, J. L., \& Wolfson, C. (2005). A Hybrid Qualitative Method for Pretesting Questionnaires: The Example of a Questionnaire to Caregivers of Alzheimer Disease Patients. Research in Nursing \& Health, 28, 419-430.

https://doi.org/10.1002/nur.20095

Organisation for Economic Co-operation and Development (OECD) (2013). OECD Guidelines on Measuring Subjective Well-Being. Paris: OECD Publishing.

Park, N., \& Peterson, C. (2006). Moral Competence and Character Strengths among Adolescents: The Development and Validation of the Values in Action Inventory of Strengths for Youth. Journal of Adolescence, 29, 891-909. https://doi.org/10.1016/j.adolescence.2006.04.011

Pasquali, L., Gouveia, V. V., Silva dos Santos, W., Nunes da Fonsêca, N., Moura de Andrade, J., \& Souza de Lima, T. J. (2012). Perceptions of Parents Questionnaire: Evidence for a Measure of Parenting Styles. Paidéia, 22, 155-164.

Pavot, W., \& Diener, E. (1993). The Affective and Cognitive Context of Self-Reported Measures of Subjective Well-Being. Social Indicators Research, 28, 1-20. https://doi.org/10.1007/BF01086714

Peterson, C. (2013). Looking Forward through the Lifespan: Developmental Psychology. Sydney: Pearson Higher Education AU.

Peterson, C., \& Park, N. (2009). Classifying and Measuring Strengths of Character. In S. J. Lopez, \& C. R. Snyder (Eds.), Oxford Handbook of Positive Psychology (pp. 25-33). New York: Oxford University Press.

https://doi.org/10.1093/oxfordhb/9780195187243.013.0004 
Peterson, C., \& Seligman, M. E. (2004). Character Strengths and Virtues: A Handbook and Classification (Vol. 1). New York: Oxford University Press.

PsychCorp (2015). BASC-3 Parenting Relationship Questionnaire Sample Report (Prepared by R.W. Kamphaus \& C.R. Reynolds).

R Development Core Team (2019). R: A Language and Environment for Statistical Computing. Vienna: R Foundation for Statistical Computing

Reid, C. A. Y., Roberts, L. D., Roberts, C. M., \& Piek, J. P. (2015). Towards a Model of Contemporary Parenting: The Parenting Behaviours and Dimensions Questionnaire. PLoS ONE, 10, e0114179. https://doi.org/10.1371/journal.pone.0114179

Revelle, W. (2019). Package Psych V1.8.12: Procedures for Psychological, Psychometric, and Personality Research. Evanston, IL: Northwestern University.

Robinson, C., Mandleco, B., Olsen, S. F., \& Hart, C. H. (1995). Authoritative, Authoritarian and Permissive Parenting Practices: Development of a New Measure. Psychological Reports, 77, 819-830. https://doi.org/10.2466/pr0.1995.77.3.819

Rohner, R. P., Khaleque, A., \& Cournoyer, D. E. (2012). Introduction to Parental Acceptance-Rejection Theory.

Rosseel, Y. (2012). Lavaan: An R Package for Structural Equation Modeling. Journal of Statistical Software, 48, 1-36. http://www.jstatsoft.org/v48/i02

https://doi.org/10.18637/jss.v048.i02

Ryan, R. M., \& Deci, E. L. (2000). Self-Determination Theory and the Facilitation of Intrinsic Motivation, Social Development, and Well-Being. American Psychologist, 55, 68-78. https://doi.org/10.1037/0003-066X.55.1.68

Ryan, R. M., \& Deci, E. L. (2001). On Happiness and Human Potentials: A Review of Research on Hedonic and Eudaimonic Well-Being. Annual Review of Psychology, 52, 141-166. https://doi.org/10.1146/annurev.psych.52.1.141

Ryff, C. D. (2014). Psychological Well-Being Revisited: Advances in Science and Practice. Psychother Psychosom, 83, 10-28. https://doi.org/10.1159/000353263

Sanders, M. R. (2012). Development, Evaluation, and Multinational Dissemination of the Triple P-Positive Parenting Program. Annual Review of Clinical Psychology, 8, 345-379. https://doi.org/10.1146/annurev-clinpsy-032511-143104

Saris, W. E., \& Satorra, A. (1993). Power Evaluations in Structural Equation Models. In K. A. Bollen, \& J. S. Long (Eds.), Testing Structural Equation Models (pp. 181-204). Newbury Park, CA: Sage.

Schwartz, G. (1978). Estimating the Dimension of a Model. Annals of Statistics, 6, 461-464. https://doi.org/10.1214/aos/1176344136

Seabridge, S. D. (2014). Examining the Link between Parenting and Child Problem Behaviors in American Indian Families. Stillwater, OK: Oklahoma State University.

Seligman, M. E. (2002). Authentic Happiness: Using the New Positive Psychology to Realize Your Potential for Lasting Fulfillment. New York: Free Press.

Seligman, M. E. (2011). Flourish: A New Understanding of Happiness and Wellbeing and How to Achieve Them. London: Nicholas Brealey.

Seligman, M. E. P. (2004). Can Happiness Be Taught? Daedalus, 133, 80-87. https://doi.org/10.1162/001152604323049424

Seligman, M. E., \& Csikszentmihalyi, M. (2000). Positive Psychology: An Introduction. American Psychologist, 55, 5-14. https://doi.org/10.1037/0003-066X.55.1.5

Seligman, M. E., \& Pawelski, J. O. (2003). Positive Psychology: FAQS. Psychological Inquiry, 14, 159-163. 
Seligman, M. E., Railton, P., Baumeister, R. F., \& Sripada, C. (2016). Homo Prospectus. Oxford: Oxford University Press.

Sha, S., \& Ackerman, T. (2018). The Performance of Five Reliability Estimates in Multidimensional Test Situations. In L. A. van der Ark et al. (Eds.), Quantitative Psychology (p. 196). Proceedings in Mathematics \& Statistics, Berlin: Springer.

Shelton, K. K., Frick, P. J., \& Wootton, J. (1996). Assessment of Parenting Practices in Families of Elementary School-Age Children. Journal of Clinical Child Psychology, 25, 317-329. https://doi.org/10.1207/s15374424jccp2503_8

Sheppard, M. (2010). The Parent Concerns Questionnaire: A Reliable and Valid Common Assessment Framework for Child and Family Social Care. British Journal of Social Work, 40, 371-390. https://doi.org/10.1093/bjsw/bcn163

Singh, K., Junnarkar, M., \& Kaur, J. (2016). Measures of Positive Psychology, Development and Validation. Berlin: Springer. https://doi.org/10.1007/978-81-322-3631-3

Stalikas, A., \& Kyriazos, T. A. (2019). Research Methods and Statistics Using R. Athens, GR: Topos.

Stalikas, A., Kyriazos, T. A., Yotsidi, V., \& Prassa, K. (2018). Using Bifactor EFA, Bifactor CFA and Exploratory Structural Equation Modeling to Validate Factor Structure of the Meaning in Life Questionnaire, Greek Version. Psychology, 9, 348-371. https://doi.org/10.4236/psych.2018.93022

Steger, M. F., Frazier, P., Oishi, S., \& Kaler, M. (2006). The Meaning in Life Questionnaire: Assessing the Presence of and Search for Meaning in Life. Journal of Counseling Psychology, 53, 80-93. https://doi.org/10.1037/0022-0167.53.1.80

Steiger, J. H., \& Lind, J. C. (1980). Statistically Based Tests for the Number of Common Factors. Paper Presented at the Psychometric Society Annual Meeting, Iowa City, IA.

Tobach, E., \& Schneirla, T. C. (1968). The Biopsychology of Social Behavior of Animals. In R. E. Cooke, \& S. Levin (Eds.), Biologic Basis of Pediatric Practice (pp. 68-82). New York: McGraw-Hill.

Triple-P International (2014). Five Steps to Positive Parenting (Children 0-12 and Teenagers 12-16). 3028 JD Feb 2014. Ontario, Canada: Triple-P Positive Parenting Program.

Tucker, L. R., \& Lewis, C. (1973). A Reliability Coefficient for Maximum Likelihood Factor Analysis. Psychometrika, 38, 1-10. https://doi.org/10.1007/BF02291170

Ullman, J. B. (2013). Structural Equation Modeling (Chapter 14). In B. Tabachnick, \& L. Fidell (Eds.), Using Multivariate Statistics (pp. 681-785). Boston, MA: Pearson Education Inc.

Velicer, W. F. (1976). Determining the Number of Components from the Matrix of Partial Correlations. Psychometrika, 41, 321-327. https://doi.org/10.1007/BF02293557

Verhoeven, M., Deković, M., Bodden, D. \& van Baar, A. L. (2017). Development and Initial Validation of the Comprehensive Early Childhood Parenting Questionnaire (CECPAQ) for Parents of 1 - 4 Year-Olds. European Journal of Developmental Psychology, 14, 233-247, https://doi.org/10.1080/17405629.2016.1182017

von Bertalanffy, L. (1976). General System Theory: Foundations, Development, Applications (Rev. ed.). New York: George Braziller.

Wang, J., \& Wang, X. (2012). Structural Equation Modeling. Hoboken, NJ: Wiley, Higher Education Press. https://doi.org/10.1002/9781118356258

Wang, L. L., Watts, A. S., Anderson, R. A., \& Little, T. D. (2013). Common Fallacies in Quantitative Research Methodology. In T. D. Little (Ed.), The Oxford Handbook of 
Quantitative Methods (pp. 718-758). New York, NY: Oxford University Press. https://doi.org/10.1093/oxfordhb/9780199934898.013.0031

Wehmeyer, M. L., \& Little, T. D. (2009). Self-Determination. In S. Lopez (Ed.), The Encyclopedia of Positive Psychology (p. 19). Chichester: Blackwell Publishing Ltd. https://doi.org/10.1093/oxfordhb/9780195187243.013.0033

Werts, C. E., Linn, R. N., \& Joreskog, K. G. (1974). Interclass Reliability Estimates: Testing Structural Assumptions. Educational \& Psychological Measurement, 34, 25-33. https://doi.org/10.1177/001316447403400104

Whiteman, S. D., McHale, S. M., \& Soli, A. (2011). Theoretical Perspectives on Sibling Relationships. Journal of Family Theory and Review, 3, 124-139. https://doi.org/10.1111/j.1756-2589.2011.00087.x

Wickham, H. (2019a). Package Haven v2.1.1.

Wickham, H. (2019b). R Package Dplyr v0.7.8.

Wickham, H. (2019c). R Package Tidyr v0.8.3.

Willis, G. (2005). Cognitive Interviewing: A Tool for Improving Questionnaire Design. Thousand Oaks, CA: Sage. https://doi.org/10.1037/e538062007-001

Xie, Y. (2019). R Package Knitr v.1.2: Dynamic Report Generation.

Yuan, K.-H., \& Bentler, P. M. (2000). Three Likelihood-Based Methods for Mean and Covariance Structure Analysis with Nonnormal Missing Data. Sociological Methodology, 30, 165-200. https://doi.org/10.1111/0081-1750.00078 


\section{Appendix}

\section{NICOMACHUS-Positive Parenting Questionnaire (NPP)}

Below are twenty statements about you and your family, with which you may agree or disagree. Using the $1-5$ scale below, indicate your agreement with each item by indicating that response for each statement.

$1=$ Absolutely Untrue

$2=$ Mostly Untrue

3 = Can't Say True or Untrue

$4=$ Mostly True

$5=$ Absolutely True

1) I encourage my child to keep his/her sense of humor even in hard times

2) I encourage my child to fight for what is fair

3) I incite my child to always tell the truth

4) I urge on my child to retry things, he/she wasn't successful in the past

5) I incite my child to be enthusiastic with everything he/she does

6) I urge my child on reading books

7) I encourage my child to do the right thing, even when there is no personal gain

8) I encourage my child to motivate and support others when he/she participates in group activities

9) I urge my child on giving a second chance to other people

10) I am in readiness to see into my child's strengths

11) Some of my child's strengths stand out more clearly than others

12) I can say I am sufficiently aware of my child's strengths

13) I encourage my child to study something related to his/her character strengths

14) I make sure that my child's extracurricular activities cultivate his/her character strengths

15) I do not have problems with my marriage or personal relationship

16) I have a good relationship with my extended family members

17) My husband/partner supports me when I need it

18) I help my child do his/her homework

19) I get my child to his/her extracurricular activities

20) I often get briefed by my child's teachers

\section{Scoring:}

- Total Score: Add the responses and then divide by 20 to get the overall score or

- Factor Score: Divide the sum of factor items by the number of items in the factor.

\section{Factors:}

1) Nurturing Values (NV, items 1 - 9)

2) Strength Identification \& Boosting (SIB, items 10 - 14)

3) Parenting Context (PC, items 15 - 17) 
4) Involvement (I, items 18 - 20)

Permission for Using the Scale: Although copyrighted, the scale may be used as long as proper credit is given 